\title{
Perceptions of Entrepreneurs and Innovators regarding Radical Innovation: Fundamentals, Requirements, and Method
}

\author{
Dylan WALLACE and Brian BARNARD* \\ Wits Business School, University of the Witwatersrand, South Africa
}

\begin{abstract}
The study examines the perceptions of entrepreneurs and innovators regarding radical innovation (RI). Emphasis was squarely on the perceptions innovators hold of RI, to lay bare psyche and mindset in this regard. Given this specific focus, experience of RI was not deemed necessary, only general entrepreneurship and innovation experience. It is believed that any sufficiently experienced innovator would have constructed some perception of RI, and that this greatly impacts attitude towards RI. The study considers comprehension regarding general RI principles, perceived requirements for RI, and general knowledge of RI method. Overall, incremental innovation (II) dominates, and RI enjoys little regard and preference. This is due to the perceived risk, lack of support, and consequently, the cost to the entrepreneur. It may also be impacted by innovation style, and broader factors, like innovation culture and environment. Understanding of RI is simultaneously promising and lacking. There are evident gaps, yet signs of potential. In general, RI is seen as very risky, perceived requirements for RI are conventionally appraised, and understanding of RI method is not comprehensive. It is believed that RI thinking and method itself can form the middle ground and bridge between II and RI. The entrepreneur versed in RI thinking and method, may more willingly consider RI, once he is able to apply RI thinking and method to II, and benefit from it. Also, sustained and sustainable RI requires proper innovation culture and environment.
\end{abstract}

Keywords: entrepreneurship, innovation, radical innovation, innovation perspective, innovation culture

JEL Classification: O30, L26

\section{Introduction}

Innovation makes up a key component of present-day business environments and competition. It may constitute a core competency, and may give the organization a competitive advantage. It promises disruption, breakthrough, and new ways of conducting business and adding value (Weerawardena and

\footnotetext{
${ }^{*}$ Corresponding Author:

Brian Barnard, Wits Business School, University of the Witwatersrand, South Africa

Article History:

Received 2 February 2019 | Accepted 1 April 2019 | Available Online 11 April 2019

Cite Reference:

Wallace, D. and Barnard, B., 2019. Perceptions of Entrepreneurs and Innovators regarding Radical Innovation: Fundamentals, Requirements, and Method Expert Journal of Marketing, 7(1), pp.42-71.
}

This paper has previously been included in an open access repository - SSRN. 
Sullivan-Mort, 2001). The ability to radically innovate impacts the ability of businesses to compete in competitive markets, especially in survivalist economies. Radical innovation (RI) has significant impact on the activities of firms, markets, and product development.

(Fostering) innovation is of utmost importance to small to medium sized firms, especially for growth. Smaller business start-ups with an entrepreneurial focus may have an innovation-based advantage over larger organisations. Innovation, particularly the ability to radically innovate, is becoming increasingly important for these businesses.

Innovation in itself brings about many challenges, and requires proper knowledge in order to navigate it, particularly in naturally aggressive markets (McDermott and O'Connor, 2002). Irma (2011) states that "companies of different sizes require different types of innovation" (p. 68). This alludes to the innovation potential and capabilities of businesses, based on approach, resources, and difficulties faced. RI is a complex process, and is characterized by more prominent changes (Norman and Verganti, 2014). Innovation potential should equally be determined by innovation perspective.

The purpose of the study is to further investigate the perceptions held by entrepreneurs regarding RI - how entrepreneurs see RI, its practice, and the obstacles in this regard. Little is known about innovation perspective, particularly with regards to RI, and especially within smaller organisations. The study focuses on the fundamentals of RI, its contrast with II, and how the progression between II and RI (Walker, 2010) is viewed by entrepreneurs. Emphasis is placed on the defining paradigms and knowledge that exist and drive innovation, and that (may) limit the inclination to further adapt and practice RI. This includes knowledge of RI thinking, skills and method.

The study addresses the following research question: what are the perceptions of entrepreneurs and innovators with regards to radical innovation? It covers the following sub-questions:

- How do entrepreneurs perceive radical innovation and its feasibility?

- What are the requirements of radical innovation, as experienced by entrepreneurs?

- How capable are entrepreneurs when it comes to radical innovation: how sophisticated are entrepreneurs in terms of radical innovation methods and technique?

Such an understanding will help to assess whether the perspective held by entrepreneurs regarding $\mathrm{RI}$ is healthy, or whether it is something that requires further development.

It is not a requirement of the study that participants have RI experience, but simply that they have adequate innovation experience, and thus have developed extensive innovation perceptions. Considering both the strong similarities and differences between entrepreneurs and innovators, the study does not readily differentiate between the two, and uses the terms interchangeably. By implication, both the innovator and entrepreneur practice and participate in innovation.

\section{Literature Review}

\subsection{Defining Radical Innovation}

II can be understood as the gradual improvements that are made within a given frame of solutions, described by Norman and Verganti (2014) as: "doing better what we do already", whereas RI is more focused around a change of frame: "doing what we did not do before" (p. 82). The major difference that can then be identified between the two forms of innovation, is whether or not innovation can be perceived as a continuous modification of previously accepted practises, or whether it is new, unique, and discontinuous.

Much of the focus that is currently being emphasized sits within the realm of management communities, where radical innovation is considered to be disruptive or competence destroying in nature, or as a breakthrough, implying that it facilitates a discontinuity with the past, by bringing to the forefront new domains and paradigms, as well as promoting the potential for major changes to take place. Radical innovation may imply a concept that can take considerable time to accept, especially in settings where change is not always actively adopted. Moreover, a completely novel innovation is impossible: ideas are generally based on previous work that have constituent predecessors, sometimes through refinement, and sometimes through novel pre-existing ideas. Three criteria have been identified for innovation to be deemed radical: 1) The invention needs to be novel and dissimilar from current inventions; 2) There needs to be uniqueness; 3) The invention must be adopted and influence future inventions (Norman and Verganti, 2014). These criteria play a pivotal role in developing higher order innovations that serve to create new industries, products, or markets.

Green et al (1995) has stated that "radicalness is a perception of organisational members and depends largely on the amount of experience people in the organisation have with innovation that they are adopting and developing" (p. 204). If innovation guides firms into areas where knowledge is limited on new 
technologies or novel routines are demanded of the organisation, the innovation is likely to be seen as more radical. However, with little previous knowledge and uncertainty, risk becomes a key factor to take into account. These innovations will comprise of technological advancements, significant enough that no increase in scale, efficiency, or design can make older technologies competitive, but rather make obsolete the old, and permit entire industries and markets to emerge, transform, or disappear (Koberg, Detienne, and Heppard, 2003).

\subsection{Common Factors of Radical Innovation}

\subsubsection{Meaning}

Meaning in the context of innovation considers the interpretation of user needs and behaviours through new perspectives, that lead to innovation. Analysis of design intensive manufacturers, such as Alessi, Artmeide and other leading Italian firms, have shown that the process of innovation is not so much centred in the observation of customer needs and requirements, but rather through the application of strategy. This strategy is known as design driven motivation, and it aims to elicit radical change through the symbolic and emotional content of products, i.e. their meaning and languages, through deep understanding of broader societal changes, culture and technology. Rather than having user requirements as the driving force behind innovation, design driven innovation is pushed by the firm's vision regarding possible new product meanings and languages that could potentially diffuse society (Verganti, 2008).

\subsubsection{Design and Design Research}

The purpose of design driven research is to envision new meanings that are to be applied in product development: The primary aim is to create new knowledge regarding meaning, forming a deep understanding of why people buy products, and how one could go about transforming products into items that people buy for other reasons (emotional, symbolic, playful, etc.), as much as for its functional purpose.

From an innovation perspective, design driven research is distinct from Human-Centred Design (HCD). The HCD process contributes more to II, because it commences from existing user needs. Norman and Verganti (2014) have delineated this process through two steps: 1) It starts through the analysis of user needs, and the search for an appropriate technology (or methods) that can better satisfy them, or product language is updated to respond to existing trends; 2) An iterative process is then carried out whereby rapid prototyping and testing of each cycle is conducted, developing a more refined, more complex prototype. This process seeks to guarantee that user needs are met, resulting in a product that is both usable and understandable. (Only) by forcing the HCD process into multiple, simultaneous directions, it can generate and facilitate the development of multiple ideas, increasing the possibility of a different application space, and ultimately the possibility of RI.

\subsubsection{Technology}

Tellis et al (2009) state that, "at the national level, greater investment in R\&D is likely to yield greater access to new product ideas for firms in the economy; the spill over of knowledge created by such spending is likely to benefit firms operating throughout the economy" (p. 5). This spillover will in effect alter knowledge creation.

Sood and Tellis (2005) note three types of technological change that can occur: platform, component, and design. Platform innovation is defined as the emergence of new technologies based on scientific principles that differ from existing technologies. Component innovation is more concerned with new parts or materials within the same technological platform. Lastly, design innovation is focused on the reconfiguration of linkages and component layouts within the same platform. Furthermore, platform innovation results from component or design innovation.

A central, practical problem faced by managers is knowing when a new technology will replace an older one, and when to shift investments from the current to the future technology. The performance of a new technology generally starts below that of an existing technology, crossing the performance of the older one during its life cycle, and ending at a higher plateau (Sood and Tellis, 2005).

\subsubsection{Resources}

Sorescu et al (2003) state that "radical innovations and the technology necessary to generate them have become increasingly complex, and their undertaking requires sizable resources" (p. 85). For the reasons mentioned, larger corporations may be better positioned for radical innovations; specifically, dominant firms enjoy economies of scale in both marketing and research and development, where there is a far more efficient use of research resources. This enables firms to dedicate a larger portion of resources to specific 
projects focused on development and innovation, suggesting that RI is catalysed through well-funded, sophisticated research labs, where a lot of emphasis is placed on technologies of the future.

\subsubsection{Culture}

Culture can be seen as a set of core attitudes, values or practices that are collectively shared amongst members of a collective entity, such as a nation or firm. There are three predominant aspects of national culture that contribute towards driving innovation: A Nation's religion, geographic location, and the values of its citizens. Organisational or corporate culture, on the other hand, can be embedded in national culture, where shared attitudes and practices amongst a firm's members are mutual. There are three firm attitudes and practices that drive innovation: the willingness to cannibalise assets, future orientation, and tolerance of risk. The practices that engender and sustain these attitudes consist of the empowerment of product champions: the empowering of individuals with resources to research, explore, and build onto future technologies. Additionally, two of the fundamental components that foster culture and maintain internal markets, involve internal autonomy - the extent to which divisional management enjoys decision-making authority within the firm relative to the corporate office - and internal competition - divisions or groups of employees within the firm competing amongst themselves in order to identify and build on promising technologies (Tellis, Prabhu, and Chandy, 2009).

\subsubsection{Government and Macro-Factors}

The prevalence of innovation across nations can be attributed to the corporate factors of innovation that help to explain national levels of innovation. These factors include skilled labour, capital, government, and culture, all contributing to a firm's ability to innovate. Government policy impacts innovation within firms that operate in the particular country. Policies and government legislation can encourage and enhance the collaboration between universities and industries. This can contribute to the transformation of research that occurs in universities, that can potentially be commercialised. In addition, it can result in graduates whose skills are closely attuned to the innovative tasks that firms are faced with (Tellis, Prabhu, and Chandy, 2009).

\subsubsection{Innovation Types}

Discontinuous innovation has been identified by McDermott and O'Connor (2002) "as the creation of a new line of business, both for the firm and for the marketplace (p. 425). Innovation may be measured as the potential to influence the marketplace, and to introduce a new set of performance features that offer a significant improvement in known performance, or offer a significant reduction in cost. There are two types of innovation whereby firms seek to strengthen their market position: 1) Introducing breakthrough technologies and advancing with big leaps, and 2) Identifying and developing markets that were originally not well observed. The latter places more emphasis on identifying and developing markets that did not exist before. Through their attempts to innovate in these ways, these firms face a number of challenges. The challenges include ensuring delivery of perceptible benefits, managing the threat of cannibalisation, and lastly, overcoming market resistance to technology.

User led innovation comes about through consumers and intermediate users who develop their own enhancements to products, that manufacturers are not providing to their market segment. The result is that the user is essentially becoming and acting as the innovator. This can serve as an insightful research tool that leads designers to RI. Also, developments and findings that are brought about accidentally, can propel designers in new directions and areas of design, whereby RI is brought about unintentionally. Three dimensions of innovation have been identified, that are used to describe different types of innovation: 1) Technology-push innovation, which emanates from radical changes in technology, without changing the meaning of a product; 2) Meaning-driven innovation, which comes from the comprehension of subtle and unspoken dynamics in socio-cultural regimes; 3) Technology epiphanies introduce a radical change through meaning, enabled by the emergence of new technologies or the use of existing technologies in new contexts (McDermott and O'Connor, 2002).

Sorescu et al (2003) note that "two common dimensions underlie most definitions of the construct of radical innovation" (p. 83). The first dimension is predominantly concerned with the extent to which the needs of a customer can be better fulfilled by existing products, and the second focuses on the incorporation of new technologies into already existing products. Products that show radical innovativeness are high on dimensions of technology, marketing, or a combination of technology and marketing, or contain more innovativeness, but maintain the core technology that is not significantly new. 


\subsection{Perspective and Creative Thinking}

\subsubsection{De Bono's Thinking Hats}

The six thinking hats that have been developed by Edward De Bono (De Bono, 2010), can be seen as a system of thinking that has the intent of increasing the perspectives applied to a problem. Through the use of the six hats model, a number of different perspectives are deliberately and subsequently applied to a problem, with the aim of excluding all forms of bias, such as personal meaning. Thus, natural bias is eliminated through the use of different hats, that are representative of a specific train of thought or approach (Mathew, 2009). This model builds on parallel thinking, in order to expand the thinking process. It assists with moving away from one idea, and creating another, by no longer being limited to a single point of view. It encourages transitioning from one style of thinking to another (Karadag, Saritas, and Erginer, 2009).

\subsubsection{Parallel, Lateral and Vertical Thinking}

Zaineb (2010) notes that parallel thinking places more emphasis on a particular aspect, or the exploration of a particular issue or problem, and expands on thinking laterally, in order to emphasise what can be, rather than what is. Parallel thinking adopts a lateral approach, and is the opposite of vertical thinking, as the latter tends to reward depth of knowledge more, and follows a systematic process of problem solving through analysis (Emma, 2014). Vertical thinking has a specific method or approach to addressing a problem. It encourages a sequential logical approach, and saves energy and time at the same time, through its logical application (TCM, 2015). Vertical thinking, however, does not contribute significantly to innovation. If there is a lack of information, then this approach will result in a dead-end (Karadag, Saritas, and Erginer, 2009). Lateral thinking seeks to address issues through ostensibly illogical methods, or "thinking outside of the box".

\subsubsection{Critical Thinking}

The primary focus of critical thinking is to critically assess the premises of a statement or argument, to evaluate reasoning in a way that appropriately reflects the necessary epistemological criteria concerning the probative forces of proffered reasons and evidence (Siegel, 2017). Thinking in a manner that is critical is important for individuals to appropriately and accurately assess what is being conveyed, and whether or not it should be accepted or rejected. It builds on intellectual clarity, rigour and curiosity in order to inform well supported and insightful beliefs (Ennis, 1964). The methods of critical thinking encourage individuals to seek other hypotheses, explanations, conclusions, and sources, in order to determine if the conclusions being put forward, based on the premise or argument, are in fact accurate in any way (Kincheloe, 2000).

\subsubsection{Counter-factual Thinking}

The primary function of counter-factual thinking centres around the management and coordination of ongoing behaviour, and the thoughts surrounding the alternatives to outcomes that have occurred in the past. When thoughts are focused on what might have been, it provides for and facilitates improvement for and of the future, as counter-factual thoughts are archetypally activated by a failed goal, and they specify what might have been done in order to achieve the goal (Dator, 1998). This type of thought generally tends to produce counter-factual thoughts after failure has occurred, rather than after a success and, therefore, counter-factual thinking can be closely related to emotion, social perceptions, and self-understanding (Mercier, et al., 2016). Counter-factuals tend to focus on alternative outcomes that may be perceived as better alternatives to what might be, also known as upward counter-factuals; or as worse than actuality, known as downward counter-factuals. It often entails evaluating future performance, by modifying everyday occurrences, resulting in counter-factual thought processes, as being based on conditions that might have happened, that take the form of conditional propositions (Roese, 2000).

\subsubsection{Problem-based Learning}

Problem-based learning (PBL) attempts to solve problems through experience, using knowledge from groups. It focuses on problems that don't necessarily have a correct or well-defined solution. PBL is an enhanced thinking approach that builds on problem solving skills and collaboration, to produce knowledge and intrinsic motivation (Kilroy, 2004). This focus on learning is more about reflecting on experiences, to assist in developing strategies and to construct knowledge that will enhance outcomes and the resolution of problems. In order to solve problems, individuals are required to develop clinical reasoning processes, and assimilate the relevant information, so to establish the necessary solutions (Hmelo-Silver, 2004). 


\subsubsection{Lateral Thinking Methods and Techniques}

Lateral thinking techniques include the search for alternatives, challenging labels, fractionism, and exposure from other fields and reversal. In searching for alternatives, leaders are encouraged to go beyond what is obvious. Challenging labels requires the root cause of the problem to be brought into question by reframing. Fractionism focuses on the breakdown of complex problems in nature, in order to expose novel solutions, or to group solutions according to the issues at hand. Exposure from differentiated fields involves using best practices in other fields such as informatics, mathematics, and engineering.

(Butler, 2010) has argued that assumptions regarding how the world works are challenged by asking the right questions. It starts with broad questions, and moves to more precise questions; it sorts through the information and test hypotheses. Returning to a well-reasoned logical approach will ensure that any ideas that have been proposed, are able to stand up to analysis, logic, and reasoning. This approach requires experience in lateral thinking, but is effective in refining ideas. In the natural search for alternatives, one is generally looking for the best possible approach. Still, it is best to consider many solutions, rather than going with the first solution. The lateral search goes beyond that of the natural search, as it seeks out as many alternatives and solutions as possible. The deliberate generation of alternatives proves to be a good starting point for identifying solutions to problems, without the need to first go deeper into problem solving (Inayatullah, 2008).

\subsubsection{Deconstruction and Construction}

With the potential of further exploration through or during problem solving, a number of concepts related to deconstruction (genealogy, distancing, and alternative pasts) bring about perspectives that allow for the dissemination of texts (something that can be evaluated: a book, a world view, a movie, a person someone who can be understood), in order to question it, and to highlight the visible (evident) and the invisible (implied). Deconstruction is a focal point on the history and progression of paradigms, assisting in identifying which discourses have been hegemonic, and how the term under study has travelled through various discourses. Distancing, which is contrasted against the disinterest of empiricism and the mutuality of interpretive research, allow for the theoretical link between post-structural thought and future studies to be established. Alternative pasts and futures focus on essentially the reordering of the past, through the reordering of knowledge, which undoes particular categories, similar to that of deconstruction and genealogy, in the sense that it focuses on specific categories, such as "civilization" or "stages in history" (Inayatullah, 1998).

In reference to the work done by Inayatullah (1998), it was noted by Kilduff (1993) that "the world is not a stage. Rather, it is text, and the dynamics of this can be studied as a series of relationships between textual levels" (p. 14). Deconstruction is thus the works on interpretation of phenomena and the world, not to question science, truth, logic, and philosophy, but to merely point out what is ignored, assumed or disregarded, whilst revealing premises, dependencies, assumptions, and what is to be excluded. This can also be applied to both political and social contexts. The use of deconstruction is not to abolish science, truth, logic, and philosophy, but to put into question how texts and concepts are employed to systematically exclude certain categories of thought and communication. A deconstruction of text can also reveal the dependence of the text on an idealism that seeks to exclude deviations, mistakes, marginalia, and trivia. The gesture of deconstruction can be used to further explore on a precise level what the text has neglected, and to show that what is excluded is normally implied in the categories covered by the text. The implications that are inherent to the deconstruction of readings are, therefore, not limited to textual language, but can have farther reach into the political and social contexts in which the text is placed and exists (Kilduff, 1993).

Constructivism is a philosophy that tends to advocate knowledge through construction in real-life, or real-life like experiments, that foster learning. Knowledge is not necessarily transmitted text, but gained through learning. The concept allows for mental models of the world to be developed through practical construction. The primary concept centers on the construction of tangible artefacts that aids understanding. Inquiry-based learning (IBL) is another concept that is closely related to constructionism, as this allows learning through asking questions and finding answers, rather than listening to streams of pre-digested facts (Boytchev, 2015).

\subsubsection{Complexity Theory}

Some of the concepts of lateral thinking align with those of complexity theory. Hernandez and Varkey (2008) state that "complex adaptive systems, composed of a network of agents, have significant interactions amongst its various building blocks" (p. 26). Cilliers (2005) has summarised the scientific characterisation of complex systems as operating under specific conditions, and not as equilibrium. The 
system is made up of many components that are simple in nature, and the output of the components are a function of their inputs. The structure of a complex system allows it to behave in complex ways, and do not necessarily scale or behave in a linear fashion. Complex systems (CS) are open systems, and in order to gain a better understanding of its nature, it's crucial to understand the environment within which it operates.

In order to model CS, the complexity must be reduced. This often results in features of the system going unnoticed. The problem that often arises as a result of this, is that that which is left out, interacts with the rest of the system in non-linear ways, making it difficult to predict the effects of the initial reduction in complexity, in order to model the system. Due to this, it is challenging to gain substantial knowledge of certain frameworks. There is no possibility of stepping out of the complexity, as we are finite beings. We tend to choose our frameworks, and as a result this must be continuously revised, as it will always be only provisional (Cilliers, 2005).

\subsection{Strategic Foresight and Radical Innovation}

Rorhbeck and Shwarz (2013) define foresight as the ability to recognise developments prior to them becoming trends, to identify patterns before they emerge as constructs, and to further grasp social currents that are likely to have an impact. Strategic foresight (SF) can be used to assist with contrasting the developments of a known issue or trend. SF is aimed at identifying emerging issues for which no previous data is available, and therefore forecasting would not be possible. It is taken that strategic foresight can also contribute to RI (Lettl et al, 2006). Consequently, the methodologies of strategic foresight are further discussed below.

\subsubsection{Structural Analysis}

Godet (2008) notes that "structural analysis is a collective process which requires the participation of multiple participants" (p. 60). Identifying the principal elements (variables) is the primary objective of structural analysis, whereby teams are able to determine whether each element is influential or dependent vis-à-vis on one another. Internal, personal, and outside expertise play an influential role in the domain being studied. Structural analysis comprises of three phases: 1) Creating an inventory of variables; 2) Describing relationships amongst the variables; and 3) Identifying key variables. Relationships among variables are identified through a two-dimensional matrix, called a "Structural Analysis Matrix", and ranked (direct, indirect and potential). The key objective of structural analysis is to note, and validate through a team, the importance of variables believed to play a dominant role in the system. One of the benefits to this is that the team can also verify hypotheses related to how the system functions. The group's original hypotheses concerning the variables of importance, their influence, and whether or not they are dependent, may also be corroborated (or contradicted).

\subsubsection{Stakeholder Analysis}

The purpose of strategic stakeholder analysis is aimed at recognising and resolving the conflicts that occur among actors pursuing their own interests (Godet, 2008). The interaction between these parties play a role in conditioning the evolution of a system under study. The method used to analyse and evaluate these actors is known as the MACTOR (Méthode ACTeurs, Objectifs, Rapports de force). This tool evaluates the relationships that are deemed critical amongst actors, as well as their convergences and divergences. The analysis, through the construction of a table of actor's strategies and the MACTOR tool, allow for the evolution of systems to be described based upon the key actors, and the variables over which they have control (Godet, 2008). A veritable card is created for each actor, with their objectives, parameters, constraints, and projects under development, as well as the maturity of their project life-cycles. The card also contains the means of action available to each actor with regards to completion of goals, and vis-á-vis other actors.

Godet (2008) continues that a matrix is constructed from the "table of actors' strategies", revealing the direct influence of and between the participatory actors. Relationships are calculated based on the means of action of each actor, as well as the direct and indirect (an actor being able to act on another through an intermediary) means of actions. There are five levels of relationships among actors, that are classified according to the degree of influence: 1) An actor may have little or no influence on another; 2) An actor may cause a disturbance amongst the others; 3) An actor may jeopardise the projects of other actors; 4) An actor may jeopardise the mission of another; 5) An actor may jeopardise the very existence of another. The actors and their positions are plotted using a two-dimensional matrix, where the axes represent influence and dependence.

The confrontation amongst actors in terms of their projects, goals, and available means, reveal a 
number of strategic stakes. The divergence and convergence around these objectives are used to characterise the relationships amongst these actors. The matrix "actors versus objectives" indicates the attitudes felt by each actor towards a given objective, with agreement $(+1)$, disagreement $(-1)$ or neutrality $(0)$. The possibility of conflicts and alliances is identified and exposed through this method (Godet, 2008).

\subsubsection{Morphological Analysis}

Morphological analysis (MA) is a method for the rigorous structuring and investigation into a set of relationships in non-quantifiable socio-technical problem complexes, also known as wicked problems or social messes. The method involves the creation of a discrete parameter space for a problem complex that will be investigated, as well as defining the relationships between parameters on the basis of internal consistency. These internal spaces are called the morphological field. These fields can be treated as an inference model. MA deals with the structure and arrangement of parts of an object, and how they conform to create a whole or Gestalt (Ritchey, 2005).

The object in question can take the form of the physical (i.e. an organism, ecology or anatomy), social (organisation or institution) or mental (i.e. linguistic forms, concepts or systems of ideas). The method starts with the identification of parameters for a range of states, setting parameters against one another, and noting the probabilities and outcomes (Ritchey, 2005).

\subsubsection{Casual Layered analysis}

Cook et al (2014) state that "causal layered analysis is a tool to expose hidden assumptions and help create a new narrative that facilitates the desired change" (p. 531).

The purpose of causal layered analysis (CLA) is to seek and unpack, in order to look deeper into the future. Four constituent layers make up CLA: The first involves the litany or day-to-day future - the commonly accepted ways in which things are, or should be. At this level, solutions to problems are often short-term. The second dimension is far deeper, in that it looks at the social, economic, and political causes of issues. The third dimension entails culture or worldview. This is concerned with the big picture - the paradigm informing what we think versus what is real or not, and the cognitive views used to understand and shape the world. The fourth dimension is the myth or metaphor concerned and associated with the (our) deep, unconscious story (Inayatullah, 1998).

A challenge arises when conducting research that moves up and down the dimensions, and as a result is inclusive of different ways of knowing. CLA focuses less on the spatiality of futures, in contrast to techniques such as emerging issues analysis, scenarios and backcasting, and focuses more on the vertical dimensions of layers of analysis of futures studies. CLA opens up room for articulating constitutive discourses, which can then in turn be shaped as scenarios. From a civilization perspective, it is crucial to expand on the guiding metaphors and myths used to envision the future. This perspective delves into deeper assumptions about the future, specifically the "non-rational". CLA includes this metaphorical dimension, and links it with other levels of analysis. It is used as a starting point, assuming that there are multiple levels of reality and knowing (Inayatullah, 1998).

\subsubsection{Anticipatory Action Learning}

Anticipatory action learning follows a process of collaboration, whilst remaining within the bounds of an epistemological framework of participation. It differs from that of futures research, in that it is less driven by expert forecasts, and more adapted to participatory learning processes, particularly through questions and questioning, in order to glean further knowledge. This category of futures study is one that bares its head through the questioning process, as it is based on known categories of participants. It does, however, not accede to critical theory, but extracts from the actors' own epistemological categories. The future is made up of various dimensions, that include the exploration of the possible (agency and imagination), probable (historical structures) and preferred (where we seek to go) futures. Futures in relation to innovation is thereby not just out there, a blank space, but rather a space-time-person coordinate that has already been created, and is continuously in the process of being created. Through this process, the future is illuminated through iterative questioning and answering, and if undesired, a search for alternative futures ensues (Inayatullah, 2006).

\subsubsection{Visioning and Backcasting}

Visioning and backcasting are two ways of delineating normative futures, and then locating the mechanisms by which they could be achieved (Slaughter, 1997). Visioning begins with the identification of organisational problems, past successes and preferred futures. This process follows a workshop through 
which scenario planning is adopted, however, more restrictive in nature than backcasting, where backcasting tends to ignore potential futures, and proposes an ideal future. Through the process of visioning, scenarios are explored, in order to obtain an idea of how the future works, with the necessary steps and resources being identified in the present, that could result in the desired direction being taken, in order to get to the future. Here the process also takes into account practical futures, and underlying assumptions as to whether the factors driving futures can be ignored or not, and whether or not it is critical.

The approach to backcasting is one that is explicitly normative, with a focus on complex, long-term issues, rather than simpler, more close-up ones. It provides for a dialogue about long-term policies and frameworks, for the exploration and design of appropriate strategies. One of the distinguishing key characteristics of backcasting analysis, is attaining desirable futures - normatively determining the physical feasibility of the future, and the policy measures that are required in order to reach it. Backcasts are not intended to reveal or indicate what the future is likely to be, but rather act as an indicator of the relative feasibility and implications of various policy goals. Backcasts are selected based upon criteria that have been defined externally to the analysis, whilst with forecasts, emphasis is placed on discovering the structural features of the world that can cause a future to come about. The emphasis of backcasting is, therefore, more focused on determining the freedom of action, from a policy sense, with respect to possible futures. In order for backcasting to be done accurately, future goals and objectives need to be well defined, and must then be used in scenario planning. The scenario is evaluated based on its physical, technological, and socio-economic feasibility and policy implications. Scenario planning forms an iterative process, in order to resolve any inconsistencies in the physical, to mitigate adverse economic risk, as well as any social and environmental impacts that come about through the analysis (Robinson, 1990).

\subsection{Paradigms}

Paradigms are a particular view of or based on a collection of interrelated beliefs, that are shared by people, like scientists, i.e. agreements about the understanding of problems and phenomena. The way in which problems are defined, in part, often determines how strategies are developed in order to solve them. Anderson and Funnel (2005) identify four insights into the nature of paradigms: 1) The underlying beliefs of a current paradigm form part of the epistemological foundation of professional education; 2) The beliefs that are learnt during professional education capture the minds of student's; 3) Paradigms are often resisted by professional communities; 4). A paradigm shift resembles a Gestalt shift - a perceptual transformation. One of the more challenging aspects in fostering the adoption of new paradigms, is that paradigms become embedded and exert a huge influence on interaction and thinking. Often a paradigm becomes embedded in one's consciousness, to the extent that they are hidden. Individuals are often socialised to a paradigm during their professional education or career, i.e. they adopt a worldview through role models and mentors, without the full understanding of the paradigm, resulting in a specific view of reality and not reality itself. The paradigm, therefore, becomes part of their profession and often personal identity. Once used in practice, paradigms become the glasses through which reality and the world is seen (Anderson and Funnell, 2005).

Walker (2010) argues that "paradigm mentalities prove detrimental to healthy inquiry by limiting scholarly visions, curiosity, and creativity" (p. 434). Theoretical and methodological diversity is crucial when engaging anomalous evidence, in order to advance knowledge. Paradigms are born when scientific achievements have resolved debates over the foundations, assumptions, and methods in a scientific field of inquiry. This results in consensus over the fundamentals, as paradigms imply a sense of shared consciousness. Once paradigms have been forged, they provide a level of guidance in an exclusive and productive manner. A paradigm mentality can limit an open society's ability to diverge thinking, and considerably reduces the ability to incubate progressions in innovations. Refutations of paradigms, rather than small increments, show marks of progression, cultivating and encouraging open societies to encourage competition between theories, as opposed to the hegemonic reign of one paradigm, which can lead to radical innovation (Walker, 2010). In order to make progressions through innovation, disagreement between dissimilar theoretical frameworks is not only possible, but essential for furthering discoveries and catalysing innovative developments.

Lakatos focused on the development of the "research program" and the succession of theories. Linking theories, through shared commitments, in a sequence involving new and more detailed articulations, shelters them from empirical refutation. Successive theories of a programme simplify certain assumptions, whilst core assumptions remain intact. An important aspect of the research programme is that of stimulating the development of more adequate theories. As programmes progress and mature, a common reason for replacing a theory is experimental failure. To be accepted, a new theory must both accommodate and explain its success over its predecessor, whilst providing an explanation as to the data brought about exposing the 
theory in question. Additionally, good theories lead to new predictions and incremental movements towards innovation, that can be experimentally verified. Research programmes composed of successor theories that meet these goals are said to be progressive (Gholson and Barker, 1985).

\subsection{Conclusion}

From the literature it is evident that a number of factors (perspective and new thinking, resources, innovativeness, culture, macro-factors) contribute to RI and its success. It is also evident that perspective is crucial for innovation, and forms a prominent part thereof. Furthermore, perspective can be formulated and reformulated in a number of ways. Foresight and paradigms further reflect on RI perspective. Little is known with regards to how entrepreneurs think of and perceive RI, particularly in terms of what they believe is required for RI, how attainable RI is, and how they consider and approach RI in terms of methodology. Therefore, the study sets out to address the following research question: what are the perceptions of entrepreneurs regarding RI? In this regard, the following sub-questions are covered:

- How do entrepreneurs perceive RI and its feasibility?

- What are the requirements of RI, as experienced by entrepreneurs?

- How capable are entrepreneurs when it comes to RI: how sophisticated are entrepreneurs in terms of RI methods and technique?

\section{Methodology}

In order to study the perceptions of entrepreneurs regarding RI, semi-structured interviews were carried out, and purposive sampling was used. RI experience was not deemed necessary for the study, only general innovation experience, and extensive entrepreneurship experience. 10 experienced entrepreneurs were interviewed, all with at least 1 successful business, and at least 3 years entrepreneurship and innovation experience. This ensures that the interviewees would have formed comprehensive perceptions of RI. Sampling was not constrained according to industry, as the impact of industry on the study was deemed negligible. Participants were identified through professional and business networks. Interviews on average lasted 1 hour. Interviews were recorded, transcribed, coded, and further analyzed.

\section{Results}

\subsection{How do entrepreneurs perceive radical innovation and its feasibility?}

4.1.1 Definition of Radical Innovation (RI)

$\mathrm{RI}$ is seen as a new market entry that has a significant market impact. RI is turning a complacent market upside down - breaking with complacency and old ways of doing things, and breathing new life into a complacent market. RI is an unique, but profitable view or perspective. RI is getting/ gripping the attention of the market. RI is burning the ship - abandoning and making redundant current operations and products, and servicing the same market with a completely new product. RI is pioneering - being a pioneer.

$\mathrm{RI}$ is seen as a process of evolution. The innovator may have an idea of his destination, objective or goal, and make discoveries along the way. RI may follow from making an attempt to advance something in some way. A goal is set, and it may not be certain how the goal will be reached. A number of external factors equally shape the process and determine the outcome. RI may also be stumbled upon.

\section{Similarity between Incremental Innovation (II) and Radical Innovation (RI)}

Many do not really distinguish between II and RI. They simply focus on solutions to problems. The problem and the market decides whether it is II or RI. The incremental and breakthrough innovation process are seen as largely the same. The innovator generally starts the same way. External factors over the innovation process equally determine whether the outcome is incremental or breakthrough innovation. It is possible to have sudden breakthrough, but normally incremental steps are taken towards RI. RI can also be achieved or arrived at through a number of incremental changes and approaches. As he works on solutions, the innovator may make discoveries that can lead to RI. The innovator should try fast, and fail fast, and get his product to market quicker.

\section{Difference between II and RI}

It is believed that II has far more structured processes, controls and requirements, or steps. II wants to protect and secure current assets and operations. RI is seen as a lot more loose, informal, nonconformist 
and dissident. In some ways RI may even be seen as impulsive. RI does not necessarily move from a position of analysis - having done (extensive) prior analysis. RI is taken as high risk, high return. RI is prepared to take risks and suffer losses.

\section{Problems and type of innovation}

To a large extent, innovation is coming up with solutions to problems. Therefore, the problem as opportunity determines whether it is II or RI. The problem determines the process to follow. The problem determines the resources required. The problem determines the time a solution would take, and how extensive work on the solution would be. The problem determines the possible impact, effect or value. Factors like the size, scale, and maturity of the problem, as well as the attention that the problem has received, determine the outcome and nature of the innovation. It may be that a solution to the problem already exists, and that it must simply be discovered and identified. Big problems may require a lot of resources to solve. The more someone has tried to solve a problem, the more resources will likely be required to improve on the solution.

\subsubsection{Aspects of Radical Innovation (RI)}

Risk

Risk and innovation are predominantly approached from the perspective of risk to the current operations and revenue streams of the business. II is preferred, because it does not put the current business and offerings at risk.

II involves taking a number of small steps. A lot of trial and error, and piloting are done, with quick and small interventions. Risk is small and over a short period. Uncertainty is limited. Growth or returns are small, or relatively smaller than that of RI, but more certain. II offers greater clarity and certainty around customers, and markets. It can be more readily tested. It has less cost. It has less risk or uncertainty in terms of value proposition. The consequences of failure is not that great. II entails more innovation mandatory to remain competitive - continuous improvement. II may be very analytical and clinical in thinking and process. II entails: 1) Analysing and questioning systems and processes of doing things; 2) measuring performance and processes - their cost and efficiency; and 3) simply finding better ways - the easiest, simplest, most effective way of doing something.

RI involves a lot more uncertainty, and thus risk, over a prolonged period. RI has greater risk/ reward ratios, and the stakes are higher. It is possible to win or lose big. Should the innovator win, he wins big. Similarly, should he lose, he loses big. With II, there is not that much on the line. With RI it is less certain whether the innovation and product will succeed or fail. RI will be new and disruptive to the market. It may require large upfront investment. RI may require a lot of in-depth research before any implementation. RI generally requires taking calculated risk - doing enough homework to reduce the risk, but being willing to take the risk. It must be accepted that it may fail entirely with huge write-offs.

\section{Finance}

II may require less capital outlay. II is easy to finance and it can be done internally. A lot more information is available, with a proven track record. It entails less uncertainty, and a shorter investment period. A lot of existing resources and income streams can be used to fund II. If the II fails, it is likely to have less impact on the business' financials, and the business will likely be able to bare it.

RI requires significant finance over a longer period, and involves a lot more risk. RI would likely require external finance. It has extensive impact on cash flows, and the business' ability to bear it. With RI there is a greater likelihood of losing the capital investment and writing it off. RI naturally requires a greater return than II. One of the strategies around RI and financing may be to focus on getting customers on board, in order to grow the bottom line, as quickly as possible. The right shareholders should be found that are willing to wait, and that do not require regular and immediate returns, so that it is possible to innovate and build the business. Objectives and strategy should be communicated to the financial stakeholders.

\section{$R \& D$}

It is taken that there is little difference between R\&D for II and RI. There must be a clear objective or purpose, regardless of whether it is II or RI. Both entail keeping up to date, keeping your finger on the pulse of things, evaluating processes and systems, and being aware of problems and issues. Both involve reading and building comprehension, meeting different people, exposing yourself to different industries, listening to customers, understanding the market, and considering environmental factors that are taking place. The innovator should be content with not taking it too fast, or too slow. He should be content with 
small margins, which can be great margins. And he should not become emotionally over-attached and thereby complacent.

The level of research, and information or knowledge, determine the potential for growth - the level of opportunity. At the same time, the extent of $R \& D$ is in accordance and proportion to the size of the opportunity. The benefit, impact, cost and risk of an opportunity are noted. Opportunities with good impact and little risk, or simply little risk, are favoured, because there is little to lose. The innovator looks more to $\mathrm{RI}$, if the impact possible is too low.

The distinction is made between formal and theoretical innovation that is structured and process driven, and informal innovation that is less structured. It is believed that there are not really steps and a process to innovation. The innovator may have an idea of where he wants to end, and is going to try and find a path or way to reach it. Innovation also much entails putting things together that normally do not go together, or get together by themselves.

Skills, resources and costs are involved. Skills are selected and incorporated based on the objective, and the maturity of the problem as opportunity. The innovator may deliberately introduce very diverse skills for unique perspective, and may not necessarily go after relevant experience. Employees as a team should be empowered to innovate, because they have the experience, exposure, and daily interactions.

\section{Technology}

An entrepreneur's ability to invest in technology may be limited, due to resource availability. The objectives and requirements should be clearly defined, and the process should be managed from this. The entrepreneur can develop agile technology, to allow incremental steps. Technology can be used to optimise the business and its processes, and to support growth. It can help to make communication with clients more effective and efficient. The entrepreneur should keep up to date with regards to technology, and should be on the lookout for new technology all the time. To do so, he can read, have conversations, attend conferences, and scan the environment.

Technology in the context of II (incremental innovation) may simply imply technology adoption. Existing or new technology can cause and contribute to II. Simply implementing technology can result in II. II may use technology to identify ideas and solutions for gaps and problems identified. To realize RI through technology, technology may be created, or it may simply be applied and implemented, but in very unique ways. In the latter case, the technology may first have to be radically interpreted or applied - the technology must be applied in a very new way. Technology can help create the foundation for RI. RI would normally involve completely new technology. RI can start completely fresh from a technology and systems perspective, but this may require more experts and expert knowledge.

\section{Marketing}

Incremental Innovation (II) permits very planned and structured marketing. II marketing is a lot more certain, because the product and market, or customer base, are more established, and there is a lot more established market intelligence. The market is regularly engaged. Marketing focuses on increasing the current footprint or awareness. II marketing wishes to retain the customer base. II marketing entails keeping existing customers happy, by continuously improving the product offering, and not becoming complacent. New concepts are tested, by taking them to market, and getting market feedback. Valued and select customers are approached with it.

Radical Innovation (RI) entails changes, disruptions, and new and better ways of adding value. It may entail future developments - developments intended for the future. RI may instigate and cause a complete change or shift in the customer base. RI marketing have to be able to deal with this. It may have to seek and gather a new customer base. A predominant objective of RI marketing may be to break (through) into the market. It requires funding, resources, and skills. RI involves getting into the market as quickly as possible. RI marketing requires collaboration with customers, and market feedback - a lot of market intelligence. The market may not accept and be ready for the innovator's radical idea, and his idea must be checked against the market. Customer relationships and a customer base must be developed first. Customers are good marketers, and specific focus should be on customer satisfaction and word of mouth.

\section{$H R$}

Both II and RI require and share an innovation culture. Both II and RI need the right environment and must employ the right people. It entails autonomy, accountability, and room to fail and make mistakes as part of learning. Innovation must be driven from the top, and requires that failure is allowed. Knowledge, knowledge creation, being entrepreneurial and trying things, must be embraced, valued and rewarded. People 
should be trusted and given responsibility and accountability.

II is about developing and building up the team: Getting rid of dead wood, employing the right people, training people, and motivating people. II generally wants to retain the team that has been built up over time, and focuses on developing and maintaining the efficiency of the team. II seeks to retain existing skills and competencies, as well as nurturing and developing it. II focuses on skill retention, creative thinking and productivity, through culture, environment, training and development, and rewards and motivation.

RI seeks to build up and integrate unique skills and competencies. RI wants to put together and integrate a new team with specific skills, that will be able to deliver the planned RI. It seeks to source, bring together and integrate a lot of experts and expert knowledge. A lot of expert knowledge must also be developed. Recruiting is done so that it supports current or intended products and technology. New skills or human resources are sourced and incorporated to expand the existing skills and knowledge base. Recruiting may occur based on attitude, rather than skills. In some cases, attitude is seen as more important than skills, as most skills can be learned very quickly. On the other hand, RI may require high level skills that are already developed. RI may require specialists and experts, that are accustomed to R\&D and RI processes. RI may be less open to training. RI values ambition, autonomy, tenacity, being agile, being prepared to be challenged, being humble, and flat hierarchies and structures. RI requires free-thinkers, non-conformists and revolutionaries: People with potential, who simply do not fit in that well, and who want to drive and take charge of things.

\section{Culture}

Generally, culture determines buy-in: small things that matter to people, that makes them (not) want to work in an environment. The team and empowering the team are important, because the entrepreneur can't do everything on his own.

II culture sustains, supports and self-preserves. It does not disrupt. II has a more nurturing and caring culture - a more "family" or collective culture, with more focus on long-term relationship. It entails a lot more support and risk sharing. II allows less freedom, because the objective is generally to preserve the existing business. Employees do not truly have full freedom to be creative, as some ideas would challenge and threaten the current business. People are less autonomous, self-driven, responsible, and accountable. People mostly do what is required of them, with little extra effort. People must be externally motived.

RI culture is visionary, optimistic, assured, confident, positive, persistent and tenacious. People are more self-driven, autonomous, responsible, and accountable. They are a lot more self-motivated. They are more innovative and creative. RI culture and environments allow greater freedom. RI may require more or stronger leadership or direction. People definitely can't be boxed in, and people can't be left on their own either. The organization must be comfortable with and must allow failure. RI culture champions independent thinking, responsibility and accountability, without the need to tell people what to do. It requires trust and support within the organization, with willingness to learn with and from each other in the organization. It entails an open, sharing organization. RI culture may be cultivated by constantly and actively challenging and changing things like mindsets, jobs, and job titles, to encourage innovation and growth. By constantly having strategy sessions, collaboration can be increased. Innovation is helped and driven by having a goal, objective or need. Pressure, stress, difficulty, or a problem - urgency - actually help to innovate.

Some forms of RI culture may be described as fast paced, and ecstatic or euphoric - going from one plateau to the next, and looking for the next plateau and big thing. It involves high stakes and big visions. It may entail a rather cold, performance driven, individualistic and competitive environment, that is less interested in happiness and satisfaction.

\section{Macro-Environmental Factors}

The impact of the environment is generally seen to be the same for II and RI - political, economic and social factors and environments are believed to be more or less the same for all. The speed with which markets change, develop, and evolve, impact uncertainty and the ability to innovate. The innovator has to scan the broader world, not just his immediate world. He has to read and keep up to date, and must observe the industry, the economy, the business environment, and the social world. Innovation is used in turn to counter, work in on, and change the environment.

Incremental Innovation (II) needs to be conscious of the current environment more, as it is a lot more present or current. Things like the economic climate, and (the level of exposure to) regulation, are minded in particular. II seeks to adapt to, and make the best of the environment. Innovation also takes place around adapting to the environment.

Radical Innovation (RI) may be in a better position to circumvent the current environment, because 
it is likely to only realize in the future. At the same time, RI may be more demanding and time-consuming, and may require greater management of external factors, and mitigation of external risk. Negative external factors may accumulate, and can influence the probability and speed of RI, and may threaten completion of Radical Innovation (RI).

\section{Regulatory Factors}

The country itself is following a follower strategy. It is behind and follows predominant, developed countries, like the US, UK, and Australia. This strategy is seen as good or beneficial. Its premise is that the country can simply learn from the mistakes made by the other countries.

\subsection{What are the requirements of radical innovation, as experienced by entrepreneurs?}

\subsubsection{Research and Design for Radical Innovation (RI)}

RI R\&D management tasks entail: 1) approaching the problem from multiple and various perspectives; 2) putting together a team of diverse skills; 3) assigning accountability and responsibility; and 4) delegating and distributing tasks.

RI R\&D involves developing an understanding, and thinking of and evaluating various possibilities, scenarios and options. Divergent thinking must be ensured - that the thinking is unique and different. It requires open-mindedness and open thinking, willingness to take risks, and being decisive - making the necessary decisions, and doing so timely. Suggestions, ideas, input, comments and free thinking should be encouraged and welcomed. Others should be allowed and encouraged to challenge your thinking and ideas. Its methods include brainstorming and analysis (white board exercises), stakeholder perspectives, field research, and research. At the same time, the innovator should caution against analysis paralysis.

The best person for a particular design may be people who are not exposed to or entrenched in the dominant thinking of the product, industry, or field: Someone who does not come from that particular background, but that is new to it.

It may be worthwhile to look back over time at the history of or around the business and product: What was done well, what was not done that well, and what could have been done better. It is important to really listen to customers. Product and customer experts can be utilized to incorporate insights, and to enrich designs: Designing the product may be relatively easy; designing and incorporating the customer aspect may be more difficult.

\subsubsection{Devising Radical Innovation (RI)Technology}

Rather than developing his own technology, the entrepreneur can simply synthesize technology. The development of technology itself can be outsourced. Experts - people who are specialists and (more) knowledgeable - can be brought in. Many times, technology is built in steps and stages, and over time. It is upgraded and expanded with the business, as the business moves forward.

It is important to look past niceties to the real value contribution of the technology. It should be clear how the technology is going to have a significant impact on the customer value proposition. Technology development should be accompanied by clear metrics and performance evaluation. Technology development normally starts with a clear problem definition, and then designing technology that can solve it, by starting with the simplest solution to the problem.

The innovator should keep track of new developments, also ideas and technology still in infancy. The future should also be kept in mind: It should be considered what the future might look like, and be like, also when considering all current and upcoming developments - technology and other.

Technology development can be expensive. It is possible to get bogged down and tied up in technology development. The innovator should have a timeline, and should go to market as soon as possible, with the simplest solution that solves the problem. It is easy to over design and over develop.

\subsubsection{Contribution from Experts and Networking}

A leadership style of inclusivity and collaboration is recommended. Building on experts and a network make it possible to complement and make up for weaknesses and lack of knowledge, including lack of knowledge on technology.

Heavy debate and meritocracy help to surface the best ideas. Teams should be utilized, as it is not possible to be an expert on everything. When the innovator knows his limitations, he can surmount and negate them through others. It is important to get others' insight and point of view. It develops the innovator's own thoughts, and causes him to be inspired by others' input.

Innovation is an internal competency, and innovation competency should be developed internally. It 
is best when innovation originates internally, and is cultivated internally. Innovation in non-core areas may be outsourced to external experts, networks or contacts.

Experts are a form of and extension of networks and networking. Experts can inject expert knowledge and experience, and may facilitate, particularly in fields new to the business. Experts can help to predict and pick up trends, suggest strategic direction, help with technical implementation of ideas and opportunities, and improve quality.

Partnerships are generally more beneficial than networks, and are worthwhile. It is possible to draw competencies into the organization through partnerships.

Rather than depending and relying on a few people or experts, the innovator should make use of a diverse and broad network. It may not be clear who the true expert on a subject is, and who would make the most valuable suggestions and contributions. The innovator should develop his own perspective, through reading, learning, observing, interacting, and having discussions and conversations. He should observe and scan the environment, share his views, engage, participate, and contribute. He may approach peers, and then his extended network.

\subsubsection{Transcending Boundaries and Thinking}

The innovator should stay ahead of times, and must pick up trends - local and global. He should identify new problems to solve. He should not be afraid to share information. He should make sure to be exposed to RI culture and environment - RI circles, solutions, and people. Complacency should be rejected and refused, and constant change accepted and embraced. He must commit to conscious, deliberate action to shift and expand his thinking. He should expose himself to different thinking. This includes input, like people and books, that challenge him, annoy him, and make no sense to him.

Thinking, understanding and knowledge are all important. Greater understanding opens up doors. The innovator should expand his thinking and understanding, and should question what he doesn't know. He should expand his perspective through others and diverse input - people and other. He should think about and question his ways and processes, and must challenge the way it was done and thought of in the past. He should rethink how things are done, also by incorporating and building on new knowledge. It is important to ensure proper and conducive culture.

Breaking down product and market boundaries: The innovator should really understand the customers of his products, and how they use the products. Each customer should be seen as unique. The innovator can build on this data to further develop products. He can challenge and critique the current systems and processes, and search out their flaws and shortcomings. He can move from the vantage point that the current systems and processes are not working, and are inefficient.

The innovator should analyze and understand the market, and must have a market-based problem that he wishes to solve. He should think in terms of the broader marketplace, not just the product, and should have more holistic views of products, markets and marketplaces. He can focus on removing all friction points in the marketplace. He can break down products or markets into broader or more principal products or markets that can be targeted. He may start with the problem and break it down. It is important to know who is using something, and why they are using the thing. The innovator can then move backwards from that - the people and the market - and expand on it, as it will be much reduced.

Design thinking and empathy may be applied. The innovator can put himself in the shoes of the customer. The problem, process and experience, can be broken down, to find (better) solutions for it. The purpose of products may be revised, and products and industries that are old, and that have not changed or developed over a period of time, may be targeted. The innovator may note the constraints he faces, as well as the freedom to move within the constraints, and can then design a solution around the constraints.

\subsubsection{Product and Market Paradigms}

The innovator can transition product and market paradigms by offering alternatives - creating something that is better. He must cause people to unlearn and think in new ways. The innovator can change the way people think, by pointing out shortcomings, and providing alternative thinking. The innovator can focus on developing deep understanding, or he may look for a new angle. Surfacing and being cognizant of the underlying paradigms help to transcend them. He should criticize and question with conviction and vigour, the current way of doing things, and should look for flaws in current thinking. He should be versatile in his thinking, and should cultivate a culture of questioning, open-mindedness and change.

The innovator may not know what will cause the paradigm shift, and it may be more than one thing. He should be very agile - he should try many things, and should fail fast. The more things he tries, the greater the likelihood of attaining a paradigm shift. 
The innovator can move backwards from the product, outcome or result, to its premises, to question, interrogate, and reconsider it. He may focus on removing any preconceptions, assumptions, features, particulars and attributes, and stating the basic or principal problem, without filters or preconceptions.

The innovator should have a customer focus - be very cognizant of his customers and their needs. It is pointless to reinterpret products and markets, if it is not possible to connect this to a customer need. He must ensure relevant products are being developed - that products are relevant. The innovator can again apply design thinking, and the principles of empathy, also to break down the customer or product process and experience, and to find (better) solutions for it. He may change the style, attitude, or energy of the product. He can do market research to help him.

The emotions and associations people attach to products are important. Customers are and should be directed and guided. Focus should be on selling the positive. It is possible to overload or flood customers, and products may be too much for customers.

Customers should be offered simple choices and decisions. The innovator can up-sell, can sell products in stages or steps, and can build new products onto or on top of existing products, in line with this up-selling philosophy.

A lot of products require education, as there are a lot of misconception around products in the market as well. It may benefit to better educate people, and to put people in a more informed position to buy products. Building relationship with customers helps to gain their trust, which is necessary to shape their views and beliefs.

\subsubsection{RI through Knowledge}

Knowledge is at the center of innovation. A strong relationship exists between knowledge and ideas, and ideas increase with knowledge. Possessing a lot of knowledge, particularly specific, industry knowledge, means it is likely that the entrepreneur or innovator can suggest and come up with a lot of leads and ideas. The more ideas and suggestions the innovator has, the more he can pick and choose. The innovator should interrogate as much of his ideas as possible, possibly also through delegating it or handing it over to an innovation team.

A knowledge culture should be cultivated. Knowledge is developed by 1) staying up to date; 2) through observation; and 3) from the environment; 4) making real effort to listen to your customers; 5) willingness to learn; 6) making mistakes and learning from mistakes; 7) curiosity; 8) questioning; and 9) building experience and consequently expertise in an industry or environment. It benefits to build strong teams, as a team will always be able to contain more knowledge than an individual.

Forms of knowledge and thinking that benefit innovation, include: 1) thinking about the future, and how the future might evolve and play out; 2) synergy and related thinking around how a product or its use can be extended, also based on additional and related needs; 3 ) convenience, and making products as easy to use as possible; 4) noting the gaps in products, and the things that a product does not provide or cover. The innovator may also focus more on knowledge of the innovation process, rather than product knowledge.

It helps the innovator to be a good scanner, observer, and overviewer (forming holistic representations or overviews); to have a broad interest, a diverse network, and a broad knowledge base; to read a lot; and to form synergies and partnerships with other people. He can overcome his weaknesses through other people, and again negate their weaknesses through his strengths.

\subsubsection{RI through Customers}

Customers are central to innovation and the innovation strategy. The innovator should be customer centred. Innovation and products are ultimately for customers: Customers consume products. Customers are the innovator's best R\&D department.

Customers don't know what they don't know, and customers don't know what they want. Still, customers are the ones that ultimately decide on products. Great ideas may not necessarily satisfy a real customer need. Customers should already be involved very early on in the innovation process. The innovator must be willing to consider customer feedback and opinion, even if it is challenging him, and make him uncomfortable. He must have thick skin and listen to customers' criticism. He should listen to what the market is telling him, and he should listen to what he gets wrong, even if the business is doing well.

Customers can and should contribute to RI. People decide on products, and people are continually evaluating the innovator's products. The innovator should get feedback, even if only informal feedback. He should connect with and speak to the right people, and should develop the right relationships with the right people. The innovator should be humble, honest, and open with customers. He should manage the customer's expectations, and should be clear that he is launching and evaluating a new product, and would like 
feedback. The innovator can of course also be his own customer. He can apply the perspective of a customer.

\subsubsection{RI through Wild Ideas}

Wild ideas may theoretically lead to RI, but at the same time, may not be practical. A wild idea must be proven in the market first, and it must be shown to be profitable. The notion of wild or crazy ideas is also questioned, as it is possible to learn from anything, and to contribute to, and develop or advance anything. Everything has relevance. Wild ideas contain a lot of subjective thought, which can not be right or wrong. Even the vision of the entrepreneur may be considered as a wild idea. It is possible to extract principles and thinking from wild ideas, and to benefit from that. It is also possible to advance (the principles and thinking of) wild ideas. It may simply be a matter of building sense into wild ideas, and making them (more) practical. Wild ideas are judged based on what is possible. For this reason wild ideas may be ahead of their time, and thus aid RI. If something can be imagined, it can be created. Wild ideas may thus help to introduce different and divergent thinking.

Wild ideas require free and unconstrained thinking. Wild ideas also benefit from collaboration with others. Wild ideas are evaluated based on their relevance. The power of wild ideas lays in developing the principles, premises and foundations of the wild idea or vision, and then implementing them. It may simply be a case of building momentum behind a wild idea.

Wild ideas may carry a lot of risk, and may imply taking big steps or leaps. The innovator may first focus on implementing a wild idea, before being concerned with its profitability. Or, he may work out the complete details of the wild idea first, and then work out smaller or incremental steps towards realizing the wild idea.

\subsubsection{RI through Open Innovation}

Open innovation can certainly contribute to RI. Open innovation involves collaborating with diverse stakeholders, and can provide diverse and unique perspective. There is no single genius in the world. Rather, strength lays in teams. The innovator should thus collaborate and partner with others, for innovation and to innovate. Open innovation allows the innovator to expand his perspective and input, and allows him to learn. Open innovation may allow the innovator to transition his own boundaries. Open innovation may not pose a real threat to the innovator, as IP (intellectual property) and innovation are two very different things. A business may be very clear and open about its strategy and even innovation. How it is realized, eventually becomes IP. Thus, innovation and ideas may be shared.

Involving others increases input, knowledge and perspective, and saves time. There is power in size. Size can impact innovation. Open innovation can contribute to size, and diversity. It is never really known where innovation will come from. Closed innovation has value and a place, but open innovation has the potential to overwhelm it. External sources and third parties may contribute to the entrepreneur getting a big idea. RI can come through joint ventures. Many organizations are opening their innovation platforms more.

At the same time, RI may be very much individual based. The entrepreneur comes up with the idea himself, and does not source it from or through a third party.

\subsubsection{Depth through RI Techniques}

Ideally, the idea itself should be radical enough. The innovator continually evaluates his idea, solution, and knowledge against the intended market. The idea is developed, evaluated, and tested against the market. Initially it is only necessary to secure an adequate disruption - a shift in product concept - and adequate demand for it. This can then be incrementally implemented and improved upon.

Depth may be seen as sophistication. Depth is built up. It may also constitute built-up IP. This can be achieved through planning, and skills and capacity planning. Depth can also be achieved through (building) relationships. Depth is enhanced by 1) thinking of all the possible outcomes; 2) being customer focused; 3 ) the quality of the individuals in the team; and 4) building up a balance of views, diverse views and perspectives, in the team and people around you.

The status quo should be challenged, and things should be thought of differently. Meritocracy and honest discussion should be encouraged, to surface the best agreed upon opinion, and to select the best ideas. Adequate analysis should be done, and things should be broken down. It helps to have people that actually hold the process back, and slow it down, because of insistence on detail and clarity. This typically entails people that ask questions and require details and even proof.

\subsubsection{Venture Capital}

All entrepreneurs need backing and support, one way or the other. VC's (venture capitalists) offer 
access to the resources entrepreneurs need for RI. Greater collaboration is required between entrepreneurs and VC's. VC (venture capital) is important for entrepreneurship, innovation and RI. VC facilitates innovation, as it provides entrepreneurs with resources they require to innovate. The healthier the VC system, the better, and the greater the possibility for RI. Access to resources impacts innovation, and the ability to innovate.

The VC market is perceived as simply not big enough. There is not enough liquidity in the (VC) market, and there are no real, renowned and well-known VC companies in the market. Elsewhere, businesses raise capital at the drop of a hat. It is very difficult to raise capital in SA, because of very stringent requirements. VC's are not comfortable with failure, which is unrealistic. Also, VC's eye shorter time-frames than is practical, and relative to other markets. VC's don't allow adequate time for businesses to take off.

VC's are unwilling to seed opportunities. It means entrepreneurs must carry the cost of ideas and opportunities to some extent, and for some time. VC's want to see some proof of concept, which requires funding to reach, and that entrepreneurs must then self-finance. Funds for $R \& D$ are difficult to obtain, and most of the time this must be self-financed. Funding to commercialize prototypes are also seen as scarce and difficult to obtain.

VC's may be risk adverse themselves. They don't necessarily want to help carry the risk of (radical) innovation, particularly during the early stages - idea development, R\&D and prototyping stages, and precommercialization. They make available too little or no seed capital. Business and especially VC are practiced differently in this market, relative to other markets, like the US.

At the same time, limited funds may increase the drive to succeed, because of the embedded challenge. VC may cause the entrepreneur to become complacent. He may lose his drive, and the entrepreneur may now be able to outsource his work, resulting in run-off-the-mill solutions. Some feel a lot of VC is wasteful - poorly applied and spent. In some cases, the VC does not have more experience than the entrepreneur.

Furthermore, it is not just capital that entrepreneurs require. In addition to capital, other things like support, access to markets, skills, and mentoring are required. Capital alone may not guarantee the success of the entrepreneur.

VC has an ugly side too. VC may have access to a lot of money and thus power, and may shape technology and technology development. VC can have too much power and this can have negative effects.

\subsubsection{Entrepreneurs and RI Engagement \\ Advantages and disadvantages}

Small entrepreneurs are at a huge disadvantage when it comes to RI. The problem is not ideas or coming up with ideas, but resources, or an accommodating environment. Small enterprises are not even equipped for II, let alone RI.

Smalls entrepreneurs have greater freedom to innovate, because they are not restrained by prior or legacy products. They don't need to worry about hurting conventional revenue streams or products through innovation. Small entrepreneurs have a lot of flexibility and freedom, and are less invested in and committed to their current operations and offerings. They can more easily afford and make changes. At the same time, it is not ideal for small players to come up with big ideas. Big ideas can only be launched and seen through by people with access to resources, finances, and a conducive environment.

New entrants have far greater flexibility. Entrepreneurs therefore create healthy competition for large enterprises (LE's). RI often comes from entrepreneurs and innovators, rather than LE's. LE's have too much structure and process in the way. LE's are constrained by legacy systems. This makes LE's rather inflexible. LE's are complacent, and are set in their ways. LE's will come up with a lot of excuses why something cannot be innovated, to preserve the status quo. LE's has a resource advantage though. Overall, entrepreneurs are better positioned for RI than LE's. Entrepreneurs must be innovative to make up for their size, and to survive.

However, not all entrepreneurs may be innovators. Principally, for the entrepreneur to start a business, he must believe that there is significant chance of RI - a significant market entry - to commit and take the risk of starting a business. Still, the entrepreneur may lack resources, support, appropriate platform, leadership, and mentorship. A lot of resources may be necessary to truly innovate. Nevertheless, entrepreneurs sometimes find ways to circumvent this, and to innovate regardless.

Support for entrepreneurs may be limited, and they may be committed to RI out of necessity, because II may simply not be attractive enough to win backing, investment and support. RI may be required of entrepreneurs, and may be the minimum bar - the true entry barrier or requirement.

Entrepreneurs don't have environments to realize RI. Entrepreneurship is affected by finance 
(funding), the economic climate, and skills. Some of the inhibiting factors that entrepreneurs face, include: resources, mentoring and mentorship, networks and partnerships, and environment. Nuisance factors include timing. RI may require extensive $R \& D$.

With regards to the evaluation of entrepreneurs, entrepreneurs with potential are not always spotted. The ability of entrepreneurs to come up with attractive business propositions and models, and to sell their ideas, are important.

Entrepreneurs themselves may lack skills and development: They may be poor managers, they may get too involved and attached, they may lack development, and they may lack perspective, in that they stop learning.

\section{Experienced Entrepreneurs}

Experience contributes a lot to the entrepreneur. It helps the entrepreneur come up with solutions. There are things regarding entrepreneurship that can only be learned through experience and making mistakes. One cannot be taught solutions. The entrepreneur learns what to look at, and how to come up with solutions. Experienced entrepreneur s are in a far better position to launch big ideas.

The entrepreneur should spend more time on the business, than in the business. He should spend more time thinking than doing. He must take a step back and observe what is going on a lot more. Entrepreneurs don't spend enough time on strategy and at the strategic level. Entrepreneurs don't take a step back, enough. Entrepreneurs need help with running their businesses, to free them up. Entrepreneurs may stay on for too long. Entrepreneurs may need to hand over and leave their businesses, to start something else: Businesses may have exhausted their innovation opportunities, such that it is better, and time, to start something completely new.

\section{Resources}

Even with limited funds, the true entrepreneur will still find a way to circumvent resource requirements. Entrepreneurs typically find solutions to problems, and resources simply become another problem to solve. Resource requirements can be circumvented by thinking about it differently. New and unconventional thinking are required. The entrepreneur should apply different perspective, and break with conventional thinking in terms of the resources he needs, and how to source it. The entrepreneur may find resources in places he has not looked before, or considered looking before. Resource requirements can also be circumvented through networks. Entrepreneurs need to be willing to collaborate and must have an open mind. Entrepreneurs may partner with large enterprises with a similar focus or target market, to facilitate resource sharing in exchange for innovation. Entrepreneurs should focus on their area of speciality, and should find partners to outsource or commit the rest to.

Resource abundance does not guarantee innovation, and can lead to complacency.

Time may be the biggest resource-based constraint, more than finance. The entrepreneur may simply not have enough capacity to innovate, and to implement innovations. The entrepreneur needs to make time. It helps if the entrepreneur has a number of big ideas that he explores and develops on and off throughout the day, and over time. The ideas then develop and accumulate mass. They also accumulate solutions.

Some feel resources are not fairly distributed, but only benefit a few. Resources and support are made available, but it is ill-managed and ineffectively applied, benefiting only a few. There must be better evaluation of (R)I, with better selection and screening of opportunities.

\section{Knowledge}

Successful businesses are run by individuals who really know the intricacies of the business and the industry. Among other things, his knowledge of the innovation process, affects the innovator's ability to come up with innovation - the ability to identify ideas, solutions or problems - that would be deemed as radical and disruptive, as well as his ability to grow and develop radical ideas and solutions to the level implied by RI.

Skills determine how knowledge is used and integrated into RI. His entrepreneurship and innovation skills determine what knowledge is used, and how the knowledge is used. The innovator must know how to source and use knowledge, what to do, and how to move forward. He must develop and accumulate the right skills set and skills portfolio.

Knowledge is democratized and freely available. Thus, knowledge should not be a constraining factor for the entrepreneur. It may be the view that knowledge is abundant. Yet, some feel knowledge may not be that easy to obtain. It is believed this is necessary to access and exploit the knowledge. Entrepreneurs are not reading enough. Not reading, or processing, enough quality material can inhibit one's ability to 
innovate.

To really stand a chance, the entrepreneur has to be certain his offering is distinct and unique. This requires knowledge. The entrepreneur must understand his proposition and the market. He has to sift through and assess the relevant knowledge. This implies a lot of reading, writing and reflection. He must meet and interact with different kinds of people. People are not moving beyond their networks and circle of contacts (enough). The entrepreneur should learn from people who are very different to him. He must be able to discern what is opinion and what is fact. Also, experience may be more scarce and exclusive, and thus more important than knowledge. The entrepreneur should display ongoing curiosity, and must build and expand his perspective. He should research on an ongoing basis: He should not simply research when he has to innovate. He should not just research problems, or research after having identified problems. The entrepreneur must be able to combine convergent thinking when working on problems.

Innovation is helped by being well informed - by knowledge and exposure. It helps when the entrepreneur increases his interaction - see, hear, learn, and talk more. Research may be a specific approach to innovation and entrepreneurship. A very calculated way to entrepreneurship: Having done all the homework, or thinking that all the homework is done. It is not necessarily mandatory.

\section{RI Thinking}

RI thinking equates to being highly skilled, highly knowledgeable, and very open minded. Some feel radical thinking cannot be taught. A person is born with it. RI thinking is part of one's character. Certain traits are required for RI. The innovator must be optimistic, curious, inquisitive, have a broad knowledge base, be willing to be challenged, and be able to deal with ambiguity and uncertainty - working with and on something that he knows very little about. He must be open to change and trying new things, and must be willing to learn. A culture and platform are required that are committed to implementing and advancing ideas, and not just leaving them as ideas.

The innovator should incorporate, bring together, and integrate diverse things and perspectives. He can look for solutions, and borrow knowledge and wisdom, from other and different industries, fields and contexts, and look to apply it to his own context. RI constitutes creating new (problems and) needs. RI requires a problem - the innovator has to come up with a problem. It must be a problem that can be turned into and sold as a need. It may be things people are not aware there is a problem with. RI ideally combines conceptual simplicity with structural complexity: simple ideas, but with complex systems.

Attitude is an important component of the kind of thinking that results in RI. Passion, curiosity. interest, ambition (wanting to progress and move forward), vision (being driven, self-motivated and with vision), and tenacity (trying everything and every idea) are all important. The innovator must be willing to work for benefits that he will only receive in the future. Innovators must invest in themselves and build themselves up. RI requires autonomous thinking - taking control of one's own life.

\section{Creating Disruption}

Disruption does not go and come with comfort, security, order and certainty. Although perhaps easier said than done, disruption breaks with convention. Disruption is changing the way people think or do things. The innovator must be willing to risk and take risk. He should question things, and at the same time cause people to question their ways and beliefs. Disruption reverses and must reverse complacency.

The innovator should map and understand the existing environment and the unique value propositions thereof. He can challenge traditions and culture, also the tradition and culture of doing things. He may question and interrogate premises and assumptions, and review the things said can't be done. He can turn to process innovation, and (re)evaluate the value of business processes.

The innovator should build on a team, experts and support, to back him, help him, support him, carry him, and complement his abilities. He requires constructive feedback. He may borrow from other industries, and apply it to his own. He should listen to customers and understand customer needs. He needs to find lots of people with a similar need that he can solve. He should concentrate on simplifying things, and reducing complexity, as a way to add and offer value.

He may target industries that have been around for a long time, are successful, and that are generally complacent - big, dominant, and arrogant. This may imply easy businesses with high margins, that do not require and demand efficiency to survive. He can also target industries and setups where he would not have the cost structure the incumbent has or faces. He may disrupt based on 1) the factors of competition of the market or industry; 2) the weak points or spots in the market or industry; or 3) the inflexible and unmovable factors or points in the market or industry, that naturally inhibit innovation in the market or industry. 


\section{Industry Disruption}

One view is that there are not really industries that are less susceptible to RI than others. No industry is really protected or shielded from RI. All industries can be radically innovated. Introducing a highly valued product will increase people's willingness to change and adopt. Therefore, RI can take place in any market, particularly markets selling to end consumers. Necessity products - things people really need - products that truly connect with customers emotionally, and products that are not expensive - products that are easy to buy - are also relatively open to RI. Product industries might be slower, because products are more tangible, are owned, and are more easily and more readily attached to. It is believed that industries or aspects heavily dependent on relationship, are less susceptible to innovation.

It is believed that the following industries are truly open to and susceptible to RI: 1) Service and technology based industries. Services should permit RI, but generally do less so than IT and technology industries; 2) Digital and converging markets - markets where conventional borders are blurring, and where conventional norms are changing; 3) Industries that no longer can continue in conventional ways; 4) Old industries that have been around for a while, and that are dominated by a few players, where complacency is likely; 5) Industries susceptible to automation through technology, like AI and robotics. Certain technology, like $\mathrm{AI}$ and robotics, are then seen as radical, or allowing RI.

Technology, like AI and robotics, can change the fundamentals and principles, as well as the norms and status quo, of certain industries. Fundamental technological and other forms of changes, like AI, may disrupt industries across the board. Thus, things like technology may increase susceptibility and openness to Radical Innovation (RI).

4.3 How capable are entrepreneurs when it comes to radical innovation: how sophisticated are entrepreneurs in terms of radical innovation methods and technique?

\subsubsection{Complex Systems and Radical Innovation (RI)}

Complex systems may hinder and oppose innovation, and make innovation difficult, because of dependencies - it may be difficult to isolate aspects or areas, and work in on complex systems. It is also not always possible to experiment with complex systems. From that vantage point, innovation and entrepreneurial thinking may consequently be impacted by what is ingrained - culture, tradition, systems, processes, products.

The expertise required to innovate should increase with the complexity of the system. To introduce change may be difficult. Complex systems may require experts, and bringing in experts, particularly if the continued stability of the system is important. A lot of complexity is also human in origin. Inertia, and legacy systems and processes, may point to an underlying cost and complexity associated with moving away and forward from traditional or old systems and processes.

Complex systems should be made simple. Complex systems can be broken up, even fundamentally, and not just on the surface. It helps to break down complex systems into basic components, and to then work with that. In a sense, starting over may also be viable. A number of systems become too complicated, and then start to prohibit good business practices, such that their relevance can be questioned. At that point, it becomes better to start over, rather than trying to spruce up the system.

\subsubsection{RI through Critical and Counter-Factual Thinking}

RI generally builds on a strong basis of critical thinking and counter-factual thinking. Things are questioned, and not taken for granted. Critical thinking is required to know the true problem, whether the problem is being addressed, and the effectiveness of the solution. Wrong and inefficient thinking creep into a business, when thinking is not checked, questioned, and challenged enough. Unsubstantiated thinking, premises and assumptions then usually follow.

RI requires the innovator to be critical. The innovator can only apply his mind critically, when he has exposed himself broadly, and when he has read broadly. There is value in studies and studying, and spending time analyzing problems. Critical thinking requires time. Although few do, reading and critical thinking should be seen as working. Critical thinking may also be thinking how a product, company, or industry may be redesigned from scratch, such that changes or improvements are not just made on top of the existing.

Counter-factual thinking can be used to improve and optimize business processes and structures. Counter-factual thinking serves as a way to challenge conventional, dominant and established ways of doing things. Counter-factual thinking rejects conventional and common belief, until it is proven by customers and demand. Counter-factual thinking is persistent and tenacious - counter-factual thinking will ultimately question solutions, until they achieve good results. Counter-factual thinking believes a solution is possible. It questions, and does not simply assume something is correct or optimal. It contemplates and criticizes. It 
involves in-depth thinking, considering details, and learning - asking questions and answering them.

\subsubsection{RI through Experiential Learning, Problem Based Learning or Constructivism}

RI builds on the ability to measure and to evaluate, and to learn from that. The innovator learns from his successes and mistakes. Ultimately, evaluation and testing take place in real time, and real environments.

Experiential learning is seen as an efficient innovation method, as it is one of the most engaging and enjoyable methods. The innovator may not even realize that he is learning. Opportunity should be created to learn through experiences. The less bureaucracy, the more the opportunity and chance to learn.

Problem based learning may be very practical and relevant, because a specific, relevant problem is addressed. Problem based learning may also be able to force innovation in a sense - requiring people to work on solutions to a problem, and realizing innovation that way. Problem based learning can provide and introduce some structure and process to innovation.

\subsubsection{Emerging Issues and RI (i.e. Environmental Scanning)}

Environmental scans are one of the starting points to assess opportunity, and where opportunity exists, particularly when the entrepreneur focuses on doing things better, or fixing an innate problem. Environmental scans are incorporated to identify hot spots in the industry, whether there are problems to solve, whether there is opportunity to innovate and come up with a value proposition, and whether there is good reason why a problem has not been solved to date.

In a sense, there will always be something - a challenge. It can be political or economic, etc. Challenges in the environment should be seen as constraints to work around. Also, constraints from the environment should be seen as opportunity. It is a matter of how quickly the innovator can adapt, and how flexible he is. The environment must be understood, to make sense of and bring order to it. The innovator must develop the ability to identify opportunity when scanning the environment. This does not necessarily entail scanning the environment from the context or perspective of an opportunity he is working on. Scanning is done before the innovator starts working on an opportunity, not after. Environmental scans must be done continually. The innovator should read a lot.

The extent to which RI is sensitive to the environment may vary. A business may not be very sensitive to the environment. His success may cause the innovator to become complacent. As long as the business runs, the innovator may have little reason to bother.

\subsubsection{Radical Innovation (RI) through Structural Analysis}

Structural analysis provides a form of knowledge that can enable RI ideas. Entrepreneurs are people with vision that identify opportunity in need, and fulfill that need. This means staying relevant, not becoming complacent, and staying abreast with developments related to the need, as well as other developments, like technology.

Industries and environments should be known. The innovator should form views of how the future might evolve, and what the future might look like. It is important to note how developments, like technology, will play out and have an impact. He can build on and leverage people and experts who have spent the time to look at the factors and likely scenarios. He may engage them, or follow their work. He may even question their views. He can apply scenarios produced by other companies and experts to his own context, industry, or problem, to learn from this and expand his thinking. The innovator should be curious. He should read extensively, have discussions, attend presentations and seminars, and should scan the internet and social media. He should investigate when something new arises. He must be aware of developments, and find ways to adapt to it.

The relevance of structural analysis may be industry dependent. Certain industries may be very structured, sophisticated or complex, almost to the point that the number of RI opportunities are limited. In other industries, the number of RI opportunities may be more bountiful.

\subsubsection{RI through Stakeholder Analysis}

Stakeholder analysis is seen as important, and it is believed that it can provide insight, but it is also the view that it has limitations, and innovation, as well as identifying opportunities, do not rely on it or require it. Stakeholder analysis may be useful in general, used together with scenario analysis and planning, and to enrich scenario analysis and planning. However, the nature of certain people robs the power of stakeholder analysis.

Stakeholders are seen as customers, staff and shareholders. They are integral to the innovation process. Stakeholders and their management can make or break a business. Customers are part of the 
business' stakeholders. It is important to have constructive and conducive relationships with each of the stakeholder groups. Common objectives should be found, and it must be ensured that everyone is moving in the same direction, and that everyone is collaborating. It must be ensured that there is trust.

Customers are seen as a principal stakeholder. Consequently, it must be ensured that customers understand and value the business' value proposition. Also, that value is provided to customers. Customers serve as a guideline for innovation and RI.

The existing and immediate stakeholders of the business are mainly considered, not extended or surrounding stakeholders in the environment. Entrepreneurs display general unwillingness to trust or rely on people. Some of the things seen to complicate stakeholder analysis, include: 1) power plays; 2) dishonest people; 3) unreliable people; 4) people who are not open; 5) difficulty in reading certain people and their intentions, and 6) people easily changing their mind.

\subsubsection{RI through Morphological Analysis}

Morphological analysis is seen as part of scenario planning and analysis. It is seen to form part of an environmental scan. The innovator should be conscious of issues of interest, but it does not necessarily take his predominant focus. It is important to analyze and keep up to date on issues, but the analysis may be wrong, and surprises may increase. The analysis itself may be developed and improved further. It may be of interest, and it may develop thinking, but it is not certain, and does not provide guarantees. One particular view is that it is not known what will cause RI, so trial and error is best, and there is no use to analyze (contexts) too much.

Perspective building enhances and advances understanding of current offerings. Ways to build a more holistic perspective are thus welcomed. The innovator should note developments and the possibilities, also in terms of and via new technology, and thus how a product will likely evolve with time - what and how a product will be in the future. The innovator can also pay attention to the possible integration of existing products into new products and extended products. Of relevance is the new precedents and norms that new technology and products create.

The innovator should also pay attention to the speed with which an industry changes, particularly the rate of adoption of new products and innovation. Adoption may pick up with time and education, as (customer) thinking starts to shift. It is possible that markets and environments change fundamentally, but even then there are intermediary transition phases.

Any kind of analysis should be merged with customer feedback and input. The customer should not be excluded during the process and analysis. Customers, and their needs and desires, ultimately determine how products evolve and change. It is important to note how it is possible to expand on existing products and offerings. The innovator should be cognizant of how existing offerings can extend to, can link to, and can open the door to new opportunities. The innovator can jump to new opportunities, through existing offerings, by noting the new opportunities that existing offerings suggest.

\subsubsection{RI through Causal Layered Analysis}

It is believed that causal layered analysis (CLA) help to better understand customers and their needs. However, it may not be enough on its own to innovate from. The innovator should take time to analyse his own bias and thinking. Again, the analysis should start with the customer. It must be ensured that all business units or departments, and processes, align and are aligned with the product or solution. Any problems should be identified and fixed, by again finding solutions to them. The innovator must have a holistic view of the solution and its processes. Not all the issues are always apparent.

RI mostly has and yields future benefits. The innovator can look at the types of interventions necessary in or for the future, to realize positive impact and effect - what will be necessary or needed in the future. He can examine how relevant his idea will be in the future, when it is implemented and ready, and may learn from that.

\subsubsection{RI through Action Learning}

Learning is important for the innovator. The innovator learns from and through reflection - by looking back and taking stock. He can expand on this, by also learning from the experiences and reflections of others. The greater the span or scope of learning - the base he learns from - and the faster he learns, the more likely he is to come up with ideas and RI ideas.

Action learning has good interactive process. As part of reflecting, the innovator should note what has changed, when it changed, and why it changed. The innovator can also reflect on the predictions people make regarding the future, and the eventual outcomes. 


\subsubsection{RI through Visioning and Backcasting}

Scenario planning helps to understand the future. It helps to reveal what will be relevant and in demand in the future. RI looks at the future, not the past. In a sense, it entails working on ideas that are essentially ahead of their times. Visioning is important, but execution is just as important.

The innovator may look at potential scenarios, and solutions around (existing or new) customers, their needs and their lifestyles. Customers, needs, processes, experiences etc. can be broken down into simpler components. He may consider innovating around potential scenarios, and managing their risk, also through innovation.

His vision is vital to the entrepreneur. It helps to keep him going, particularly when things are difficult. It provides direction and stability. His vision is not necessarily clear visioning. It may be deliberately broad and open-ended. Long term strategic visions and goals drive RI and radical changes. The innovator may design technology around strategic visions and goals. The entrepreneur may work in on and attempt to change mindsets, systems and processes, and jobs and responsibilities, to bring them into alignment with his vision and goal. Visioning may help the entrepreneur to finance innovation and technology.

\section{Discussion}

\subsection{How do entrepreneurs perceive radical innovation and its feasibility?}

Although not surprising, RI is hardly practiced, and enjoy little attention, preference, or regard. It is seen as risky, and too risky. Support and incentive for it seem to lack, and entrepreneurs see little reason to put considerable effort and investment into it, and to pursue it. The view is that the risk involved is perceived as simply too great. Particularly when unsupported, RI resembles more of a gamble to the entrepreneur.

The comparison of II and RI, and the predominant differences between II and RI, based on the entrepreneurs' perceptions, are captured in Table 1. Evidently, and unsurprisingly, RI is more difficult and more sophisticated than II. It presents far greater risk, however, warrants far greater reward when pursued.

Table 1.a. Comparison of II and RI based on entrepreneurs' perceptions

\begin{tabular}{|c|c|}
\hline \multicolumn{2}{|r|}{ Similarity (empirical) } \\
\hline & $\begin{array}{l}\text { More (simply) focused on solutions to existing problems. } \\
\text { Achieved through incremental steps or processes. }\end{array}$ \\
\hline \multicolumn{2}{|r|}{ General Difference } \\
\hline II & Has greater structure and follows a more set process; emphasis on protecting the status quo. \\
\hline RI & Entails more high-risk. Follows less of a formal approach, with no set way of going about it. \\
\hline \multicolumn{2}{|r|}{ Risk } \\
\hline II & Small, incremental steps. Risk easily managed. \\
\hline RI & High risk - high reward. Represents more of a gamble. \\
\hline \multicolumn{2}{|r|}{ R\&D } \\
\hline & $\begin{array}{l}\text { Little difference is seen between II and RI R\&D. Both require a clear objective and purpose through building } \\
\text { comprehension, gathering insights, and being aware of the economic and environmental changes occurring. }\end{array}$ \\
\hline \multicolumn{2}{|r|}{ Technology } \\
\hline II & $\begin{array}{l}\text { Greater focus on technology adoption, and the implementation of existing technology that can be further and } \\
\text { incrementally developed. }\end{array}$ \\
\hline RI & $\begin{array}{l}\text { Either a radical interpretation of existing technology in order to apply it in a new way, or the development of new } \\
\text { technology from scratch. }\end{array}$ \\
\hline
\end{tabular}

Table 1.b. Comparison of II and RI based on entrepreneurs' perceptions

\begin{tabular}{|l|l|}
\hline \multicolumn{2}{|c|}{ Finance } \\
\hline II & $\begin{array}{l}\text { Innovation poses insignificant risk to the business. Innovation cost is small in relation to the rest of the operations. } \\
\text { Internally financed. }\end{array}$ \\
\hline RI & $\begin{array}{l}\text { Innovation poses significant risk to the business. Innovation cost is predominant. External financing and } \\
\text { investment likely required. }\end{array}$ \\
\hline II & $\begin{array}{l}\text { Follows a more structured and linear process; focused on an already existing customer base; preserving customers } \\
\text { and pursuing satisfaction. }\end{array}$ \\
\hline RI & $\begin{array}{l}\text { Introduces market disruption. Needs to acquire new customers, and develop a new customer base. Requires } \\
\text { funding, resources, and skills. }\end{array}$ \\
\hline \multicolumn{2}{c}{ HR } \\
\hline
\end{tabular}


Wallace, D. and Barnard, B., 2019. Perceptions of Entrepreneurs and Innovators regarding Radical Innovation:

Fundamentals, Requirements, and Method. Expert Journal of Marketing, 7(1), pp. 42-71.

\begin{tabular}{|l|l|}
\hline II & Focuses on retaining employees and skills, and developing and maintaining efficiency. \\
\hline RI & Seeks to build up and integrate expert knowledge and skills. \\
\hline \multicolumn{1}{|c|}{ Culture } \\
\hline II & Sustainable and well defined; focused on maintaining the status quo. \\
\hline RI & Ambiguous; fluid; under development. A focus on autonomy, responsibility and freedom. \\
\hline \multicolumn{1}{|c|}{ Macro-Environment } \\
\hline & $\begin{array}{l}\text { Viewed as the same for both II and RI. Involves scanning and understanding the market and surrounding } \\
\text { environment. } \\
\text { The country has a follower strategy, following other dominant countries around the world. Allows the country to } \\
\text { learn from others' mistakes. }\end{array}$ \\
\hline
\end{tabular}

On a number of fronts, little distinction is made between II and RI. For many things, and in many instances, II and RI process, method, and technique are seen as following the same pattern. Examples of this include R\&D, technology, and environmental factors. Particularly in the area of innovation method and $\mathrm{R} \& \mathrm{D}$, this is troublesome. More sophisticated method is anticipated for RI, in line with its inherent nature. Given the fact that RI is more fundamental in nature, its underlying and accompanying thinking is expected to warrant more intricate thought and practice. This, however, is lacking and this type of thinking is absent.

Perhaps separate and distinct from arguments around risk of and support for RI, is the matter of innovation technique, and preferred innovation technique. This in turn may be correlated with risk preference or appetite. Innovators may simply prefer an innovation style that is more aligned with and conducive to that of II, rather than RI. RI may require a lot more deliberation, which innovators may not be willing to commit time to and for. They seem to prefer a quick, empirical, trial and error method of innovation, rather than a more intellectually intensive, rational and abstract approach.

In some ways, RI is perceived and understood correctly, and in others, the responses instigate an impression of ignorance, likely due to lack of experience and exposure. Fundamentally, the greatest barrier to RI is relevance - to the entrepreneur, RI simply lacks practical relevance. This is likely because of the perceived risk it involves, coupled with a lack of support. Due to the risk and lack of support, RI is perceived to be unattainable, or impractical. This in turn, means that innovators simply "shut off" when it comes to RI. On the other hand, one would have liked to see innovators more knowledgeable on RI thinking and method, so that this could be considered for and applied to II. The practice and application of RI thinking and method to II can easily become and form the middle ground and bridge between II and RI. The innovator's innovation preferences, and his perception and willingness in terms of RI, may readily change when he is experienced in RI thinking and method, and its value, through having applied it to, or in the context of, II. Because RI is not actively practiced, perceptions of RI are ill-informed on a number of grounds and in a number of areas.

The biggest factors inhibiting RI are associated with resource availability, such as funding and time for thinking. It is taken that funding or resources are also an antecedent of thinking, in that greater access to funding would likely automatically spur RI thinking. Thus, in short, support is another fundamental antecedent of RI.

\subsection{What are the requirements of radical innovation, as experienced by entrepreneurs?}

The requirements for RI, based on the perceptions of entrepreneurs, have been encapsulated and delineated by four primary aspects: 1) innovation style, 2) original thought and divergence, 3) incongruity and dichotomy, and 4) technicalities. The prerequisites of RI are significantly shaped by innovation orientation, and it is also discussed from this vantage point. To a large extent, the perceived prerequisites of RI, or simply innovation, are determined by innovation perspective, vantage point, and orientation. When entrepreneurs discuss their innovation orientation, and the requirements of radical innovation, gaps and anomalies surface and become evident. This questions whether the entrepreneurs' innovation orientation would permit RI. At the same time, this is hardly unexpected, given a strong inclination towards and preference for II. Naturally, their discussion of the requirements for RI, strongly reflects the requirements for Incremental Innovation (II).

\subsubsection{Innovation Style}

Although evidently a number of vantage points and knowledge sources are used for perspective, and although open-mindedness is largely practiced, and diverse skills and expertise are incorporated, knowledge and perspective generated for the purpose of innovation, lack depth, and are more aligned to II than RI. This is understood to be largely due to a lack of overall relevance ascribed to RI. There seems to be an over- 
reliance on certain channels: Emphasis rests on customers and teams.

Table 2.a. Requirements for RI: Innovation style

\begin{tabular}{|l|l|}
\hline \multicolumn{2}{|c|}{ Innovation Style } \\
\hline Approach problems from various perspectives. & $\begin{array}{l}\text { Break down products and the market to identify and } \\
\text { propose alternatives. }\end{array}$ \\
\hline Create teams with skills diversity. & Be agile and try different things. \\
\hline Synthesize technology. & Think of all possible outcomes. \\
\hline Build on experts. Utilise subject matter experts. & $\begin{array}{l}\text { Utilise collaboration and networking. Develop networks } \\
\text { and partnerships. }\end{array}$ \\
\hline Use experts to pick up trends or provide insights. & Extract principals and thinking from wild ideas. \\
\hline Stay up to date with trends and market changes. & Develop the premise and foundations of wild ideas. \\
\hline Identify gaps in products and markets. & Maintain a strong customer focus. \\
\hline Think about where the future is taking us. & $\begin{array}{l}\text { Target industries that have been in existence for a while } \\
\text { (identify their weak points). }\end{array}$ \\
\hline Develop and build new synergies. & $\begin{array}{l}\text { Focus on industries that can no longer operate } \\
\text { conventionally, or that are susceptible to automation. }\end{array}$ \\
\hline
\end{tabular}

\subsubsection{Original Thought and Divergence}

A number of sources are utilized and incorporated into the innovation effort, but depth appears to be shallow, with an over-reliance on certain channels (customers, networks, and stakeholders). On the other hand, certain channels are under-utilized. It is perceived that customer input has a significant influence over the innovation process. Although healthy in general, in excess this may prevent innovation from further developing in the future - going forward - as its impact on the possibility of RI is questioned. The present is also favoured over the future, and future possibilities, which is a much more prominent RI channel and perspective. Future scenarios, possibilities, and options are hardly considered and built upon. The overall view is that the innovator displays too little in-depth and original thought.

Table 2.b. Requirements for RI: Original thought and divergence

\begin{tabular}{|l|l|}
\hline \multicolumn{2}{|c|}{ Original Thought and Divergence } \\
\hline Encourage people to unlearn and change their thinking. & Develop an open mindset. \\
\hline Develop deep understanding. & Encourage free thinking and exploration. \\
\hline Challenge the status quo. & Cultivate ambitious thought. \\
\hline $\begin{array}{l}\text { Constantly be curious, and seek new ways of doing } \\
\text { things. }\end{array}$ & $\begin{array}{l}\text { Use passion as a driver to innovate. Practice and maintain } \\
\text { optimism (be optimistic). }\end{array}$ \\
\hline Utilise feedback and contributions from customers. & Question premises, principles, beliefs, assumptions, etc. \\
\hline $\begin{array}{l}\text { Seek and constantly build knowledge, also through } \\
\text { networks. }\end{array}$ & Fail fast in order to react to new opportunities. \\
\hline Understand customers and the markets you serve. & Build up a balance of views and thinking. \\
\hline
\end{tabular}

\subsubsection{Incongruity and Dichotomy}

II and RI present an identifiable degree and factor of inconsistency and dichotomy. The question is whether RI is really possible without implementing a true RI culture, and in response to this, the willingness of entrepreneurs, particularly experienced or established entrepreneurs, to build a native RI culture is questioned. By implication, if this were truly the case, a lot more experienced entrepreneurs should be serial entrepreneurs that start and get a venture off the ground, and then move on to the next venture. A true RI culture encourages autonomy and creativity, and permits idea generation and divergence away from the norm, which is contrary to II culture.

Table 2.c. Requirements for RI: Incongruity and dichotomy Incongruity and dichotomy

\begin{tabular}{|l|l|}
\hline $\begin{array}{l}\text { Change organizational culture to autonomous; creative; open } \\
\text { thought. }\end{array}$ & Integrate and bring together diverse things. \\
\hline Take a riskier position towards innovation. & Create new problems in order to seek solutions. \\
\hline Cultivate a culture towards advancing ideas and exploration. & $\begin{array}{l}\text { Combine conceptual simplicity with structural } \\
\text { complexity. }\end{array}$ \\
\hline Assign accountability towards innovating. & Evaluate scenarios, possibilities, and options. \\
\hline Delegate tasks of various aspects of innovation. & Map existing and future environments. \\
\hline Ideate new value propositions. & \\
\hline
\end{tabular}




\subsubsection{Technicalities}

In general, the entrepreneur is very aware and cognizant of the practicalities of innovation, and at the same time, reveals a comprehensive understanding of the potential dangers and pitfalls surrounding RI, and endeavouring to radically innovate. This does not suggest truly open, free and unconstrained thinking.

The possibility of failure seems to sway or deter innovators from exploring the unknown, and developing radically new innovations. This may be ascribable to innovation-specific, or broad, culture and environment.

Table 2.d. Requirements for RI: Technicalities

\section{Technicalities}

\begin{tabular}{|l|l|}
\hline Lack of resources, time, and support. & Surrounded by a culture not conducive to innovation. \\
\hline Too much uncertainty related to innovation, particularly RI. & Pointless to innovate if not tied to a customer need. \\
\hline $\begin{array}{l}\text { Becoming too attached to an idea and developing a sense } \\
\text { of tunnel vision. }\end{array}$ & The VC market is not big (developed) enough. \\
\hline $\begin{array}{l}\text { Lack of buy in and support from stakeholders and } \\
\text { shareholders. }\end{array}$ & $\begin{array}{l}\text { No platform or foundation for small entrepreneurs to } \\
\text { come up with big ideas. }\end{array}$ \\
\hline
\end{tabular}

\subsection{How capable are entrepreneurs when it comes to radical innovation: how sophisticated are entrepreneurs in terms of radical innovation methods and technique?}

The findings of the study may create the wrong impression. In general, the discussion of method is at a higher level than the practice of method. Methods that focus on general thinking and practical action are preferred, like that of critical thinking and action learning, while methods based upon systems, structure, and futures are disliked. Truly elaborate comprehensions and understanding of systems, their underlying factors, and players, are not really formulated or developed in depth, if at all. Yet, the findings are still partly soothing, in the sense that there are signs and promise of RI thinking. It is clear that the entrepreneurs are not completely defunct when it comes to RI thinking. Methods such as critical thinking and action learning may serve as, and form, a bridging mechanism, to help the entrepreneur to transition from a position of II to that of RI, and viewing RI in a positive light.

The below table highlights the perspective given on some of the methods and techniques an entrepreneur can consider for RI. The understanding of these methods has proven to not be well comprehended in terms of application and reason for use. Hence, it is possible to argue that entrepreneurs and innovators can still be taught innovation method and technique, and in terms of innovation method and technique.

Table 3.a. Perceptions regarding RI method

\section{Methods and Technique

Complex Systems and RI

When dealing with complex systems, it is sometimes difficult to isolate certain or specific areas and aspects.

Complex systems don't really allow for experimentation.

The innovator may require experts to work (in) on complex systems.

The system should be broken up into basic components, in order to correct it, or to further develop and enhance it.

From a perspective vantage point, the innovator may not be too concerned with systems and processes.

\section{RI through Critical and Counter-factual Thinking}

The innovator requires time and deep thought to critically analyse how to redesign a product, company, or industry.

Utilise counter-factual thinking to challenge the conventional or traditional ways of doing things, or to identify solutions.

Experiential Learning, Problem-Based Learning or Constructivism

Used as a method for engagement and learning, and building up a knowledge base.

It may force the innovator to work on a potential solution, and it can facilitate innovation this way.

\section{Emerging Issues}

Provides a starting point to be able to identify where opportunity exists, and how to approach it, in order to make an improvement.

Scanning various aspects of the environment as a whole.

Constraints in the environment should be seen as opportunities, to simply work around them.

\section{RI through Structural Analysis}

Apply the scenarios devised by other people and companies, as part of developing new innovations or opportunities.

Utilize seminars, stakeholders, and experts to surface ideas at different levels of thinking.

Develop and form an idea of how the future may look, and how to introduce innovation and new ways of thinking. 
Table 3.b. Perceptions regarding RI method

\section{RI through Stakeholder Analysis}

Use stakeholders to expand knowledge and share ideas. This encourages thought and ideation.

If stakeholders are not moving in the same direction or share a similar vision, it can inhibit or slow down the innovation process.

Utilize customers to ideate new innovations.

Stakeholders can prove to be dishonest, unreliable, and can mislead the innovator, creating a counter-productive environment for innovation.

\section{RI through Morphological Analysis}

Monitor and understand new developments, in order to identify the evolution of new products or services.

Monitor the rate of change that is occurring in both the innovator's internal and external environments.

Utilize customer feedback as part of the analysis process, in order to develop new and further insights, or to close potential gaps.

Analysis may be conducted incorrectly, leading to further complications and delays in developing and identifying solutions.

\section{Causal Layered Analysis}

Identify interventions at different levels relevant to the problem, in order to improve the future.

CLA needs to begin with the customer, in order to develop a foundational understanding of what developments should be made.

Use reflection as a basis for learning and improving.

Not only thinking, but also implementation.

Keep track of events and forecasts, and when certain milestones or activities have or have not been achieved.

\section{RI through Visioning and Backcasting}

The innovator identifies future possibilities, and begins to work on them through ideation and planning.

Identify potential scenarios, and how to instigate, circumvent or change outcomes. This may move the innovator to start working on changing mindsets or perspectives of the customer and others.

\section{Summary}

Entrepreneurs display little preference for and interest in RI, which is also evident from the small amount of attention that is placed on exploring the potential of RI. The reason for this is understood to be that RI poses too much risk, with little incentive and support accompanying it. Over and above this, it may also be that entrepreneurs are not inclined towards RI, based on things like their favoured and preferred innovation style. RI may not align with their preferences, focus, objectives, etc. That means that, even if RI were to be adequately supported and incentivized, with cost to the entrepreneur negated, entrepreneurs would still not be truly attracted or inclined towards RI.

As a result of disinterest in RI, the thinking and method pertaining to RI are not completely known or understood; certainly not at an advanced level. This is unfortunate, as it is believed that it might be possible to create a practical middle ground between II and RI, through the use of RI thinking and method as a bridging mechanism between II and RI. The view is that RI thinking and method can contribute towards enriching and enhancing II practice, without insisting on the practice of RI. If the innovator and entrepreneur is able to apply RI thinking and method to II, and benefit from it, he is likely to reconsider RI and his stance towards RI.

The question is therefore raised as to whether or not entrepreneurs demonstrate advanced thinking, particularly innovative thinking. Furthermore, do entrepreneurs need advanced thinking to be successful? Or, from a pragmatic or rational point of view, can they benefit from it? If this is in fact the case, how can and should entrepreneurs best be convinced of this? At the same time, what constitutes advanced entrepreneurial thinking? And how would one measure and define advanced entrepreneurial thinking?

\section{Future Research}

Future research can further examine the following:

1. RI support, and RI support programmes: given that support is a significant antecedent of RI, and cost (to the entrepreneur) is a significant deterrent of RI, research can examine the optimal incentivising and support of RI. What does the optimal RI platform look like? How should entrepreneurs engaging in and participating in RI, be supported, and incentivized? And how should the cost of RI on the entrepreneur be negated? 
2. The possibility of (creating a) middle ground between II and RI: noting the impact of RI thinking and method on (entrepreneurs') innovation and creativity, particularly in pro-II contexts. The belief is that official RI thinking and method can and should enrich II practice. Hence, the proposition is that, when assimilated, official RI thinking and method can enhance the creativity and innovativeness of the II-prone entrepreneur: Without having to "switch to" or practice RI, the II-prone entrepreneur, well trained in RI thinking and method, would be more innovative and creative than the II-prone entrepreneur not trained in RI thinking and method, based on II standards.

3. The extent and impact of innovation preference: RI practice or non-practice may equally be grounded in innovation preferences. This may particularly correlate with risk preferences. Even if RI is supported, and the cost of RI to the entrepreneur is negated, the entrepreneur may simply not be interested in practicing and engaging in RI, due to preference. The factors that impact and shape innovation and RI preference can be investigated further.

4. The extent and quality of RI thinking: To what extent do (II-prone) entrepreneurs have RI ideas, or simply big ideas, and to what extent do (II-prone) entrepreneurs recognise RI opportunities? In these cases, what are the quality of the RI ideas and opportunities?

5. Culture and RI: the impact of culture, particularly societal or national culture, on RI practice.

6. Entrepreneurial education and RI: further investigating the teaching of RI, and teaching advanced courses in entrepreneurship, that covers RI, particularly to experienced entrepreneurs as well. regards to RI?

7. Government RI policy: what would constitute optimal government policy and strategy with

\section{References}

Anderson, R. M. and Funnell, M. M., 2005. Patient empowerment: reflections on the challenge of fostering the adoption of a new paradigm. Patient Education and Counseling, 57(2), 153-157.

Boytchev, P., 2015. Constuctionism and Deconstructionism. Constructivist Foundations, 10(3), pp.355-363.

Butler, S. A., 2010. Solving business problems using a lateral thinking approach. Management Decision, 48(1), pp.58-64.

Cilliers, P., 2005. Complexity, Deconstruction and Relativism. Theory, culture and society, 22(5), pp.255267.

Cook, C. N., Inayatullah, S., Burgman, M. A., Sutherland, W. J. and Wintle, B. A., 2014. Strategic foresight: how planning for the unpredictable can improve environmental decision-making. Trends in ecology and evolution, 29(9), pp.531-541.

Dator, J., 1998. The Future Lies Behind. American Behavioural Scientist, 42(3), pp.298-319.

De Bono, E., 2010. Lateral thinking: a textbook of creativity. London, UK: Penguin.

Emma., 2014. What is parallel thinking. [online] Available at: bigvoicemanagement: http://bigvoicemanagement.com/?p=2484 [Accessed on 3 November 2018].

Ennis, R. H., 1964. A Definition of Critical Thinking. International Library Association, pp.599-612.

Gholson, B. and Barker, P., 1985. Applications in the History of Physics and Psychology. American Psychologist, 40(7), p.755.

Godet, M., 2008. Strategic Foresight La Prospective. Cahiers du LIPSOR, pp.60-102.

Green, S. G., Gavin, M. B. and Aimen-Smith, L., 1995. Assessing a multidimensional measure of radical technological innovation. IEEE Transactions on Engineering Management, 42(3), pp.203-214.

Hernandez, J. S. and Varkey, P., 2008. Vertical versus Lateral Thinking. Physician Executive, 34(3), p.26.

Hmelo-Silver, C., 2004. Problem-Based Learning: What and How do Students Learn? Educational Psychology Review, 16(1), pp.235-236.

Inayatullah., 1998. Causal Layered Analysis: Poststrucuturalism as method. Futures, 30(8), pp.815-829.

Inayatullah., 2006. Anticipatory action learning: Theory and Practice. Futures, 38(6), pp.650-666.

Inayatullah., 2008. SIx Pillars: futures thinking for transformation. Foresight, 10(1), pp.4-21.

Irma, B., 2011. Are small, medium- and micro-sized enterprises engines of innovation? The reality in South Africa. Science and Public Policy, 38(1), pp.67-78.

Karadag, M., Saritas, S. and Erginer, E., 2009. Using the 'six thinking hats' model of learning in a surgical nursing class. Australian Journal of Advanced Nursing, 26(3), pp.59-68.

Kilduff, M., 1993. Deconstructing organisations. Academy of Management Review, 18(1), pp.13-31.

Kilroy, D. A., 2004. Problem based learning. Emergency medicine journal, 21(4), pp.411-413.

Kincheloe, J. L., 2000. Making critical thinking critical. Counterpoints, 110, pp.23-40.

Koberg, C. S., Detienne, D. R. and Heppard, K. A., 2003. An empirical test of environmental, organizational, 
and process factors affecting incremental and radical innovation. The Journal of High Technology Management Research, 14(1), pp.21-45.

Lettl, C., Herstatt, C. and Gemuenden, H. G., 2006. Users' contributions to radical innovation: evidence from four cases in the field of medical equipment technology. $R \& D$ Management 36(3), pp.251-272.

Mathew, K., 2009. Events. [online] Available at: PMIKerala: http://www.pmikerala.org/events/16/ [Accessed on 3 November 2018].

McDermott, C. M. and O'Connor, G. C., 2002. Managing radical innovation: an overview of emergent strategy issues. Product Innovation Management 19(6), pp.424-438.

Mercier, H., Rolison, J. J., Straga, M., Ferrante, D., Walsh, C. R. and Girotto, V., 2016. Questioning the preparatory function of counterfactual thinking. Psychonomic Society, pp.261-268.

Norman, D. and Verganti, R., 2014. Incremental and radical innovation: Design research vs. technology and meaning change. Design Issues, 30(1), pp.78-96.

Ritchey, T., 2005. Future studies using morphological analysis. Adapted from an article for the UN University Millenium Project: Future Research Methodology Series, 14.

Robinson, J. B., 1990. Futures under glass: A recipe for people who hate to predict. Futures, 22(8), pp.820842.

Roese, N. J., 2000. Counterfactual Thinking and Marketing: Introduction to the Special Issue. Psychology and Marketing, pp.277-279.

Rorhbeck, R. and Shwarz, J. O., 2013. The value contribution of strategic foresight: Insights from an empirical study of large European companies. Technological Forecasting and Social Change, 80(8), pp.1593-1606.

Siegel, H., 2017. Educations Espistomolgy: Rationality, Diversity, and Critical Thinking. Oxford Scholarship, pp.90-93.

Slaughter, R. A., 1997. Developing and applying strategic foresight. ABN Report, 5(10), pp.13-27.

Sood, A. and Tellis, G. J., 2005. Technological Evolution and Radical Innovation. Journal of Marketing 69(3), pp.152-168.

Sorescu, A. B., Chandy, R. K. and Prabhu, J. C., 2003. Sources and Financial Consequences of Radical Innovation: Insights from Pharmaceuticals. Journal of Marketing 67(4), pp.82-102.

TCM., 2015. Defining lateral, parallel thinking, creativity and innovation. [online] Available at: Trainingcourse material: https://www.trainingcoursematerial.com/free-training-articles/creativityproblem-solving-decision-making-and-lateral-thinking/defining-lateral-thinking-parallel-thinkingcreativity-and-innovation [Accessed on 3 November 2018].

Tellis, J. G., Prabhu, C. J. and Chandy, K. R., 2009. Radical Innovation Across Nations: The Preeminence of Corporate Culture. Journal of Marketing, 73, pp.3-23.

Verganti, R., 2008. Design, Meanings, and Radical Innovation: A metamodel and a research agenda. Journal of product innovation management, 25(5), pp.436-456.

Walker, T. C., 2010. The perils of paradigm mentalities: A metamodel and research agenda. Journal of product innovation management, $8(2)$, pp.433-451.

Weerawardena, J. and Sullivan-Mort, G., 2001. Learning, Innovation and Competitive Advantage in Not-forProfit Aged Care Marketing: A Conceptual Model and Research Propositions. Journal of Nonprofit and Public Sector Marketing, 9(3), pp.53-69.

Zaineb, A., 2010. Vertical Thinking vs. Laterla thinking. [online] Available at: Commlab India: https://blog.commlabindia.com/elearning-design/vertical-vs-lateral [Accessed on 3 November 2018]. 